\title{
Resveratrol Modulation of Protein Expression in parkin-Mutant Human Skin Fibroblasts: A Proteomic Approach
}

\author{
Daniele Vergara, ${ }^{1,2}$ Antonio Gaballo, ${ }^{3}$ Anna Signorile, ${ }^{4}$ Anna Ferretta, ${ }^{4}$ Paola Tanzarella, ${ }^{4}$ \\ Consiglia Pacelli, ${ }^{5}$ Marco Di Paola, ${ }^{6}$ Tiziana Cocco, ${ }^{4}$ and Michele Maffia ${ }^{1,2}$ \\ ${ }^{1}$ Department of Biological and Environmental Sciences and Technologies, University of Salento, Lecce, Italy \\ ${ }^{2}$ Laboratory of Clinical Proteomic, "Giovanni Paolo II" Hospital, ASL-Lecce, Lecce, Italy \\ ${ }^{3}$ CNR NANOTEC-Istituto di Nanotecnologia, Polo di Nanotecnologia, Campus Ecotekne, Lecce, Italy \\ ${ }^{4}$ Department of Basic Medical Sciences, Neurosciences and Sense Organs, University 'A. Moro', Bari, Italy \\ ${ }^{5}$ Department of Clinical and Experimental Medicine, University of Foggia, Foggia, Italy \\ ${ }^{6}$ Institute of Clinical Physiology, National Research Council, Campus Ecotekne, Lecce, Italy
}

Correspondence should be addressed to Tiziana Cocco; tizianamaria.cocco@uniba.it and Michele Maffia; michele.maffia@unisalento.it

Received 11 May 2017; Accepted 19 July 2017; Published 12 September 2017

Academic Editor: Giuseppe Cirillo

Copyright (c) 2017 Daniele Vergara et al. This is an open access article distributed under the Creative Commons Attribution License, which permits unrestricted use, distribution, and reproduction in any medium, provided the original work is properly cited.

In this study, we investigated by two-dimensional gel electrophoresis (2-DE) and mass spectrometry (MS) analysis the effects of resveratrol treatment on skin primary fibroblasts from a healthy subject and from a parkin-mutant early onset Parkinson's disease patient. Parkin, an E3 ubiquitin ligase, is the most frequently mutated gene in hereditary Parkinson's disease. Functional alteration of parkin leads to impairment of the ubiquitin-proteasome system, resulting in the accumulation of misfolded or aggregated proteins accountable for the neurodegenerative process. The identification of proteins differentially expressed revealed that resveratrol treatment can act on deregulated specific biological process and molecular function such as cellular redox balance and protein homeostasis. In particular, resveratrol was highly effective at restoring the heat-shock protein network and the protein degradation systems. Moreover, resveratrol treatment led to a significant increase in GSH level, reduction of GSSG/GSH ratio, and decrease of reduced free thiol content in patient cells compared to normal fibroblasts. Thus, our findings provide an experimental evidence of the beneficial effects by which resveratrol could contribute to preserve the cellular homeostasis in parkin-mutant fibroblasts.

\section{Introduction}

Parkinson's disease (PD) is a multifactorial neurodegenerative disorder that predominantly affects the population over 65 years of age [1]. From a clinical point of view, the disease is characterized by the presence of motor deficit associated with abnormal intracellular protein deposits called Lewy bodies (LBs) and loss of dopaminergic neurons, primarily, within the substantia nigra pars compacta (SNpc) [2]. Several risk factors were identified including disease-causing mutations in a specific set of genes that mediate the autosomaldominant or autosomal-recessive forms of PD [3], among which mutations in alpha synuclein (SNCA) and in leucine- rich repeat kinase 2 (LRRK2) are responsible for autosomaldominant PD forms whereas mutations in parkin, PTENinduced putative kinase 1 (PINK1), DJ-1, and ATP13A2 are accountable for $\mathrm{PD}$ that displays an autosomal recessive mode of inheritance [3].

The most common mutant gene implicated in familial PD is parkin, and various loss-of-function mutations occurring in both alleles produce an aggressive, generally early form of PD [4-6]. Parkin is a cytosolic protein with E3 ubiquitin ligase activity, for ubiquitin-proteasome-dependent protein turnover, with a central role in mitochondrial maintenance and turnover. In response to mitochondrial damage, PINK1 induces the activation of parkin by phosphorylation. 
Once activated, parkin conjugates ubiquitin onto proteins on the outer mitochondrial membrane (OMM), leading to mitochondrial engulfment by the autophagosome via the endosomal sorting complexes required for transport (ESCRT) machinery [7-9]. Pathogenic mutations of parkin lead to the accumulation of damaged mitochondria and are associated with several cellular dysfunctions including impaired energy metabolism, deregulated reactive oxygen species (ROS) production, failure of ubiquitin-proteasome pathway, and protein misfolding [10-13].

Mass spectrometry- (MS-) based studies made possible to shed lights on the cellular pathways modified after parkin loss [14-16]. Proteomic analysis of human primary fibroblasts isolated from patients with a genetic deficit of parkin revealed that parkin is implicated in the modulation of multiple cellular functions including cytoskeleton structure dynamics, calcium homeostasis, oxidative stress response, and protein and RNA processing [17]. In this cellular model, the absence of parkin has also been associated with a specific phospholipid and glycosphingolipid lipidomic profile likely related to dysfunction of autophagy and mitochondrial turnover [18].

Current pharmacological treatments of $\mathrm{PD}$ remain largely symptomatic, and the development of new therapeutic strategies may provide effective alternative treatment options. In recent years, resveratrol has emerged as a compound conferring protective effects against metabolic and other stresses in age-related diseases, including neurodegeneration [19]. Resveratrol (trans-3,5,4'-trihydroxystilbene) a dietary polyphenol present in several medical plants [20] demonstrated multiple biological activities, including antiinflammatory properties [21], antioxidant effects [22], and neuroprotection in both cerebral ischemia and neurodegenerative diseases, such as Alzheimer's disease and Parkinson's disease $[23,24]$. Studies performed on animal models of PD have shown that resveratrol protects dopaminergic neurons from 6hydroxydopamine- (6-OHDA-) and 1-methyl-4-phenyl1,2,3,6-tetrahydropyridine- (MPTP-) induced degeneration, possibly via modulation of autophagy and proinflammatory pathways [25-27]. Ex vivo models of PD also gained interest for the preclinical assessment of the biological and medical properties of resveratrol. Previous studies of our group have shown that resveratrol treatment of parkin-null cellular model induced a partial rescue of mitochondrial functions and oxidative stress through the activation of the AMP-activated protein kinase (AMPK)/sirtuin 1 (SIRT1)/ peroxisome proliferator-activated receptor gamma coactivator 1-alpha (PGC-1 $\alpha$ ) pathway [28].

In this work, we investigated by two-dimensional gel electrophoresis (2-DE) and mass spectrometry (MS) analysis the effects of resveratrol in parkin-mutant human skin fibroblasts. The analysis of proteins differentially expressed revealed that resveratrol treatment acts on deregulated specific biological process and molecular function such as cellular redox balance and protein homeostasis. In particular, resveratrol was highly effective at restoring the heat-shock protein network and the protein degradation systems as well as the GSH/GSSG ratio, together responsible for the maintaining of the normal protein homeostasis which is essential to proper cellular function.

\section{Materials and Methods}

2.1. Cell Culture Conditions. Primary skin fibroblasts from one subject affected by an early onset $\mathrm{PD}$ with parkin compound heterozygous mutations (P1 with del exon2-3/ del exon3) and from the parental healthy subject (CTR) $[13,28]$ were obtained by explants from skin punch biopsy, after informed consent. Cells were grown in high-glucose Dulbecco's modified Eagle's medium (DMEM) supplemented with $10 \%(v / v)$ fetal bovine serum (FBS), $1 \%(v / v)$ L-glutamine, and $1 \%(v / v)$ penicillin/streptomycin, at $37^{\circ} \mathrm{C}$ in a humidified atmosphere of $5 \% \mathrm{CO}_{2}$.

In cell culture experiments, resveratrol (Sigma, R5010) was dissolved in dimethyl sulfoxide (DMSO) and used at the concentration of $25 \mu \mathrm{M}$; control cells were treated with an equivalent volume of DMSO (vehicle, $0.02 \%$ ).

2.2. Sample Preparation and Protein Separation by 2-DE. Cell pellets were dissolved in a lysis solution that contained $7 \mathrm{M}$ urea, $2 \mathrm{M}$ thiourea, $4 \%$ CHAPS, and a cocktail of protease and phosphatase inhibitors (Biotool). Samples were then sonicated on ice for three rounds of $10 \mathrm{~s}$ and processed according to the methods described before [29-31] with minor modification. Briefly, total proteins $(80 \mu \mathrm{g})$ were diluted up to $250 \mu \mathrm{L}$ with a rehydration buffer (7 M urea, 2 thiourea, 4\% CHAPS, 65 mM DTT, and 0.5\% v/v IPG buffer) and applied to IPG strips $(13 \mathrm{~cm}, \mathrm{pH} 3-10 \mathrm{NL})$. IEF and second dimension were carried out using an IPGphor IEF and a Hoefer SE 600 Ruby electrophoresis system (GE Healthcare). The IPG strips were loaded and run on a $12 \%$ SDS-PAGE gel and stained according to the protocol of Chevallet et al. [32]. Gels were scanned by Image Master scanner and analyzed by Image Master software 5.0 (GE Healthcare) using TIF format images at $300 \mathrm{dpi}$. Spot detection and matching were carried out by the software tools and corrected manually when necessary. The parameter that we used to compare gels was the volume \% (vol \%) of each spot, expressed as percentage of the spot volume over the total volume of all spots in the gel. Student's $t$-test with a set value of $p<0.05$ was used to determine significant differences in protein expression levels. Each experiment was performed three times independently.

\subsection{Mass Spectrometry Identification and Data Analysis}

2.3.1. Protein Identification by nHPLC ESI-Trap Analysis. Protein spots were manually excised from 2D gels, destained with $\mathrm{H}_{2} \mathrm{O}_{2}$, and subjected to trypsin digestion followed by identification using an nLC-MS/MS as described [29-31]. The nano-HPLC separation of peptides was performed using a Proxeon Easy-nLC (Thermo Fisher Scientific, Waltham, MA, USA) equipped with a NS-AC-10 analytical column, $5 \mu \mathrm{M}, \mathrm{C} 18,375 \mu \mathrm{M}$ OD $\times 75 \mu \mathrm{M}$ ID $\times 10 \mathrm{~cm}$ length, protected by an NS-MP-10 guard column, $5 \mu \mathrm{M}, \mathrm{C} 18$, $375 \mu \mathrm{M}$ OD $\times 100 \mu \mathrm{M}$ ID $\times 2 \mathrm{~cm}$ length (Nano Separations, Nieuwkoop, The Netherlands).

2.3.2. Protein Identification by MALDI-TOF/TOF. Spots of interest were dehydrated with $50 \mu \mathrm{L}$ of acetonitrile and trypsin digested overnight as described [29]. Resulting peptides 
were then concentrated by using C18 Zip-Tips (Millipore) and eluted with $2 \mu \mathrm{L}$ of CHCA matrix $(66 \mu \mathrm{L}$ TFA, $0.1 \%$; $33 \mu \mathrm{L}$ ACN) directly on an MTP AnchorChipTM $384 \mathrm{BC}$ plate (Bruker Daltonics). Peptides were analyzed by peptide mass fingerprinting (PMF) and MS/MS analysis with a MALDI-TOF/TOF Ultraflextreme (Bruker Daltonics) in positive ion reflector mode ( $\mathrm{m} / \mathrm{z}$ range $500-4000)$, operating at $1 \mathrm{kHz}$ frequency and controlled by the FlexControl 3.4 software. External calibration was performed using the Peptide Standard Calibration II (Bruker Daltonics). Spectra were processed using the software FlexAnalysis (version 3.4, Bruker Daltonics) and precursor ions with a signal to noise ratio greater than 10 selected for subsequent MS/MS analysis.

Compound lists were submitted to Mascot using the software BioTools (version 3.2, Bruker Daltonics). Peptide masses were compared with those present in the Swiss-Prot human protein database. Database search was performed using the following parameters: peptide tolerance, $0.05 \mathrm{Da}$; fragment mass tolerance, $0.25 \mathrm{Da}$; enzyme, trypsin; missed cleavage, one; and instrument, MALDI-TOF/TOF. Peptide tolerance was set to $\pm 1.2 \mathrm{Da}$, the MS/MS tolerance was set to $0.6 \mathrm{Da}$, and searching peptide charges were of $1+$, $2+$, and 3+ for ESI-Trap data. Moreover, carbamidomethyl (C) and oxidation (M) were chosen as fixed and variable modifications, respectively. Identified proteins were subjected to Gene Ontology (GO) analysis and protein-protein interaction (PPI) analysis by STRING software (version 10.0, http://string-db.org/).

2.4. GSH and GSSG Determination. For GSH and GSSG assay, fibroblasts were collected by trypsinization and centrifuged at $500 \times \mathrm{g}$ and then resuspended in cold $5 \%(w / v)$ metaphosphoric acid. The sample was exposed to ultrasound energy for $15 \mathrm{~s}$ at $0^{\circ} \mathrm{C}$ and centrifuged at $12,000 \times \mathrm{g}$ for 5 minutes. The supernatant was used to determine GSH and GSSG concentration using an enzymatic/colorimetric assay kit (Enzo Life Sciences) according to the manufacturer's instructions. The measurements were performed on a Victor 2030 Explorer (PerkinElmer). Total protein concentration was determined by Bio-Rad protein assay. GSH and GSSG levels were normalized to protein concentration and expressed as $\mathrm{nmol} / \mathrm{mg}$ protein.

2.5. P-SH Measurement. Cells were collected by trypsinization and centrifugation at $500 \times \mathrm{g}$ and then resuspended in phosphate-buffered saline (PBS), $\mathrm{pH} 7.4$, in the presence of the protease inhibitor phenylmethanesulfonyl fluoride (PMSF). The content of P-SH in total cellular lysate was measured with a modification of the Ellman's procedure [33]. The protein pellet was obtained by precipitation with $4 \%$ SSA and centrifugation. Next, the pellet was resuspended in $6 \mathrm{M}$ guanidine, $\mathrm{pH}$ 6.0. Optical density was read spectrophotometrically at 412 and $530 \mathrm{~nm}$ before and after $30 \mathrm{~min}$ of incubation with $10 \mathrm{mM}$ 5,5-dithiobis (2-nitrobenzoic acid). P-SH concentrations were calculated using a standard curve generated with reduced glutathione.

2.6. Analysis of Glutathionylated Proteins. Glutathionylated proteins were detected by Western blot analysis of cellular lysates after nonreducing SDS-PAGE. Cells were collected by trypsinization and centrifugation at $500 \times \mathrm{g}$ and then resuspended in PBS, $\mathrm{pH} 7.4$, containing the protease inhibitor PMSF and supplemented with $5 \mathrm{mM} N$-ethylmaleimide (NEM) to block unreacted thiol group. Total cellular proteins (50 $\mu \mathrm{g}$ per lane) were separated on $12 \%(w / v)$ SDS-PAGE and transferred to nitrocellulose membranes. Glutathionylated proteins were visualized with anti-GSH antibody (1:1000, Thermo Fisher Scientific number MA1-7620). Glyceraldehyde-3-phosphate dehydrogenase (GAPDH) (Sigma) was used as loading control. After several washes in Tween/Trisbuffered saline solution (TTBS), the membrane was incubated for 60 minutes with an anti-rabbit or anti-mouse IgG peroxidase-conjugate antibody (diluted 1:5000). Immunodetection was then performed with the enhanced chemiluminescence (ECL) (Bio-Rad, Milan, Italy). The VersaDoc imaging system was used to perform densitometric analysis (Bio-Rad, Milan, Italy).

2.7. Western Blot Analysis. Whole proteins were extracted with RIPA buffer (Cell Signaling) and quantified by the Bradford protein assay (Bio-Rad). Samples were separated by $10 \%$ SDS-PAGE and transferred to the Hybond ECL nitrocellulose membrane. The membranes were blocked overnight in Blotto A (Santa Cruz) at $4^{\circ} \mathrm{C}$ and subsequently probed by the appropriately diluted primary antibodies for $2 \mathrm{~h}$ at room temperature. Protein bands were visualized by incubating with a horseradish peroxidase-conjugated secondary antibody (Amersham, ECL Western blotting detection reagents).

\section{Results and Discussion}

3.1. Proteomic Profile Alteration in PD Fibroblasts. In our previous work, we analyzed, by 2-DE and MALDI-MS, proteins isolated from fibroblast cultures of healthy subjects and patients affected by PD [17]. This comparative proteomic approach led to the identification of several differentially expressed proteins. Here, we modified some of the experimental parameters used previously to separate proteins from fibroblast cultures, including 2-DE buffer composition and isoelectric focusing conditions, in order to increase the number of proteins separated by 2 -DE and the potential number of differentially expressed proteins identified after comparative analysis. We focused on control (CTR) and PD patient (P1) fibroblasts that we recently characterized for a variety of cellular alterations associated with the modulation of metabolic and cytoskeletal proteins $[13,34]$. With these technical improvements, we identified 15 additional differentially expressed proteins which are not yet identified in the previous work [17]. The identity of these proteins was determined by MALDI-TOF MS/MS and listed in Table 1. By combining these new results with the precedent group of identified proteins, we obtained a dataset of 44 distinct and well-annotated differentially expressed proteins that were subjected to bioinformatics analysis. GO classification and protein-protein interaction network (PPI) of this dataset are shown in Tables 2, 3, and 4 and Figure 1(b). Data showed a significant decrease, in P1 compared to CTR cells, of the expression of 


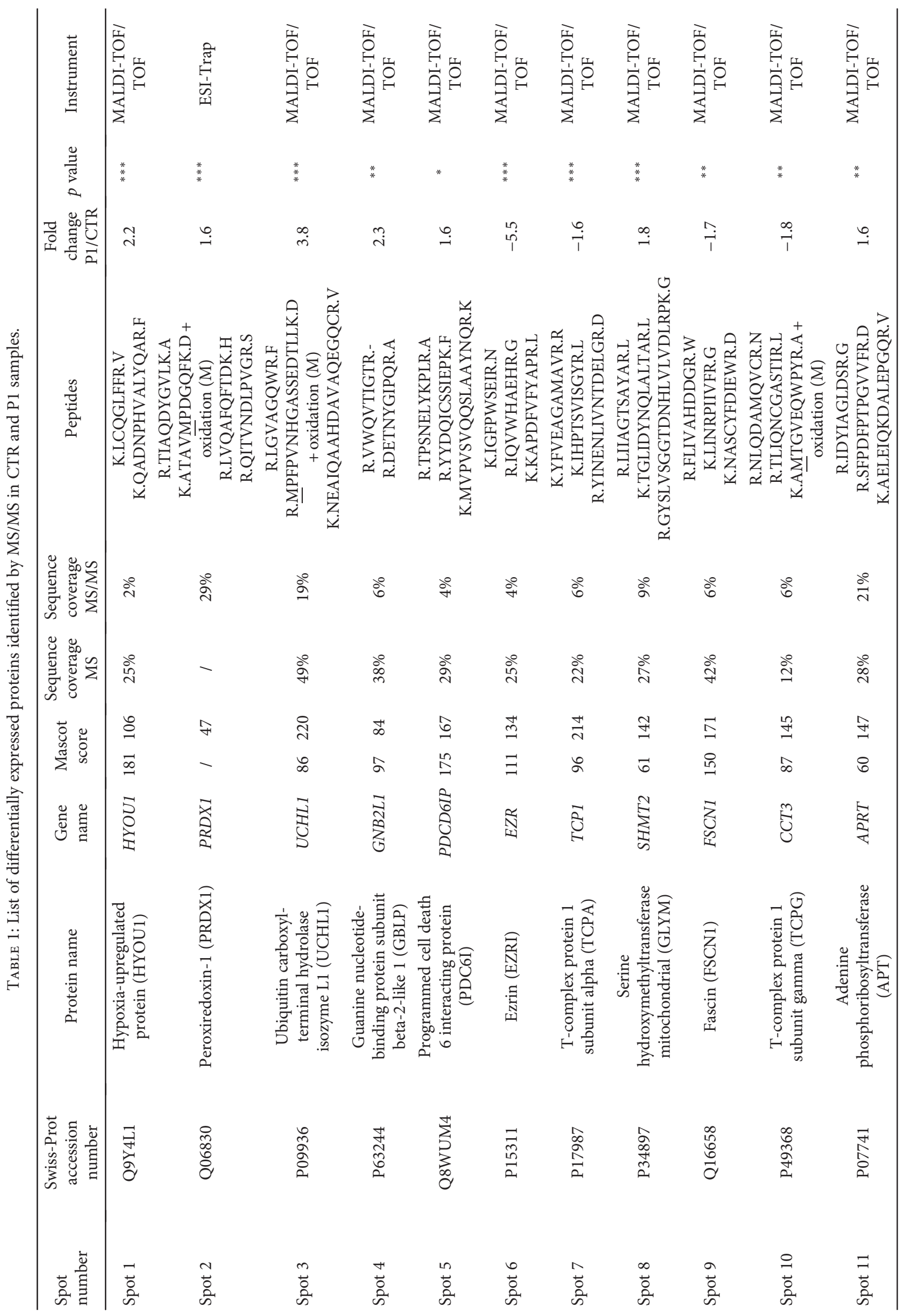




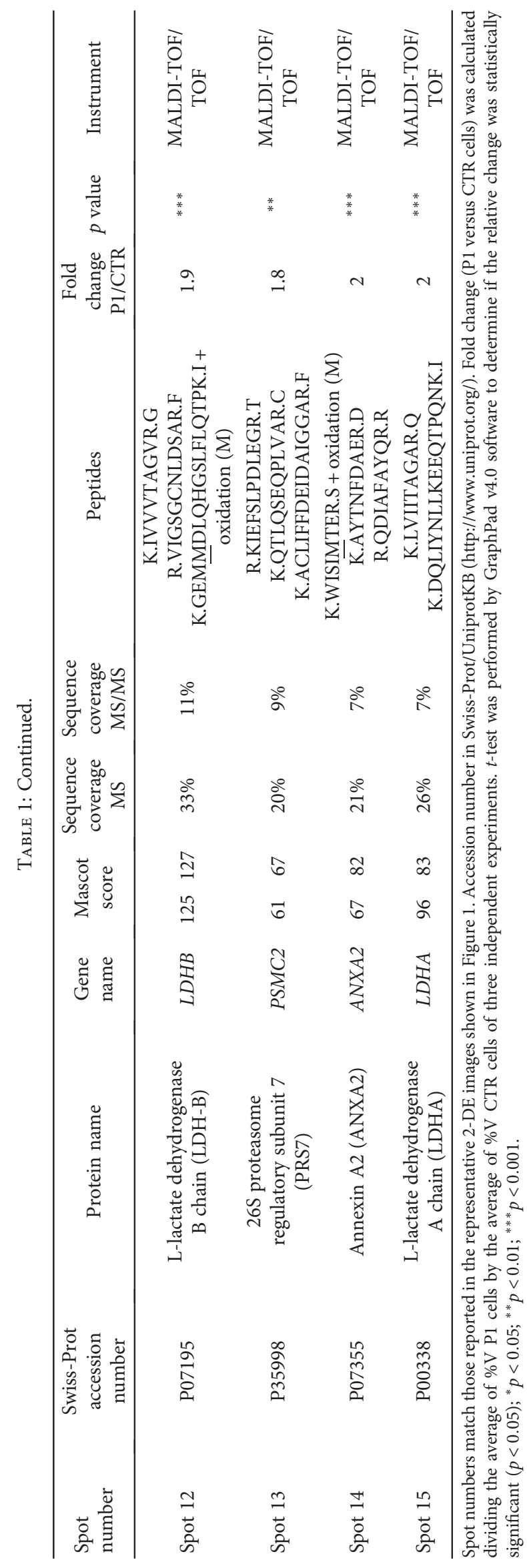


TABLE 2: List of significantly enriched biological processes in CTR versus P1 protein dataset identified by STRING software.

\begin{tabular}{lccc}
\hline $\begin{array}{l}\text { Biological process }(\mathrm{GO}) \\
\text { Pathway ID }\end{array}$ & Pathway description & Count in gene set & False discovery rate \\
\hline GO:0006928 & Movement of a cell or subcellular component & $1.1 e-05$ \\
GO:0006457 & Protein folding & 8 & $4.08 e-05$ \\
GO:0030049 & Muscle filament sliding & 5 & $4.08 e-05$ \\
GO:0006986 & Response to unfolded protein & 7 & $5.67 e-05$ \\
GO:0022607 & Cellular component assembly & 16 & $9.99 e-05$ \\
\hline
\end{tabular}

TABLE 3: List of significantly enriched molecular functions in CTR versus P1 protein dataset identified by STRING software.

\begin{tabular}{lccc}
\hline $\begin{array}{l}\text { Molecular function }(\mathrm{GO}) \\
\text { Pathway ID }\end{array}$ & Pathway description & Count in gene set & False discovery rate \\
\hline GO:0005515 & Protein binding & 30 & $1.16 e-08$ \\
GO:0005509 & Calcium ion binding & 12 & $7.71 e-06$ \\
GO:0051082 & Unfolded protein binding & 6 & $7.71 e-06$ \\
GO:0003723 & RNA binding & 16 & $1.33 e-05$ \\
GO:0044822 & Poly(A) RNA binding & 13 & 0.000172 \\
\hline
\end{tabular}

TABLE 4: List of significantly enriched molecular functions in CTR versus P1 protein dataset identified by STRING software.

\begin{tabular}{lccc}
\hline $\begin{array}{l}\text { KEGG pathways }(\mathrm{GO}) \\
\text { Pathway ID }\end{array}$ & Pathway description & Count in gene set & False discovery rate \\
\hline 04141 & Protein processing in endoplasmic reticulum & 7 & $1.25 e-05$ \\
\hline
\end{tabular}

protein related to several biological processes like those involved in cell movement or subcellular components as well as those involved in regulating, assembly and protein folding, calcium ion binding, and unfolded protein binding. Kyoto Encyclopedia of Genes and Genomes (KEGG) pathway enrichment analysis identified protein processing in the endoplasmic reticulum (ER) as significantly modified (Table 4). This includes a list of 7 well-connected proteins HYOU1, GANAB, CALR, HSPA5, HSP90B1, VCP, and HSPA8 as determined by PPI analysis (Figure 1(c)). Most of these proteins belong to the heat-shock protein (HSP) family, and all of them participate in protein folding. HSPs have become a research focus in PD because the pathogenesis of this disease is highlighted by the intracellular protein misfolding and inclusion body formation. HSPs are mainly involved, by interaction with different cochaperones, in folding nascent polypeptides to their appropriate conformation and refolding mild denatured/damaged proteins. Moreover, working together with the ubiquitin-proteasome system (UPS), they are involved in the decomposition of aberrant proteins. In addition, HSPs may possess antiapoptotic effects and keep the cellular homeostasis against stress conditions [35-38]. Evidence involving a direct role for UPS in PD results from the association between genetic mutations in parkin with familial parkinsonism [4].
It is noteworthy to highlight the high level of the ubiquitin carboxyl-terminal hydrolase isozyme L1 (UCHL1), a protein component of UPS, observed in PD fibroblasts (3.8-fold increase with respect to CTR cells) (Table 1 ). In addition to its major function related to protein degradation as a component of UPS [39], UCHL1 possesses an ubiquitin ligase-like enzymatic activity [40], placing it in a pathway potentially related to parkin. It is reported that interaction with parkin promotes UCHL1 lysosomal degradation [41] and consequently the lack of parkin could lead to the abnormal UCHL1 accumulation in PD patient cells. P1 cells are also characterized by a deregulation of redox state, and, according to previous work showing a different expression level of protein involved in oxidative stress response [17], 2-DE data revealed a significant increase of peroxiredoxin-1 (PRDX1) in P1 with respect to CTR cells (Table 1 ).

A differential expression level of energy metabolismassociated proteins was also observed. L-lactate dehydrogenase A chain (LDH-A) and B chain (LDH-B) resulted both overexpressed in P1 fibroblasts. This is consistent with the finding that P1 cells, characterized by mitochondrial dysfunctions, showed a high glycolytic ATP production, lactate level, and intracellular LDH activity [13].

Perturbation of protein folding homeostasis is a common pathologic feature of many neurodegenerative diseases, 


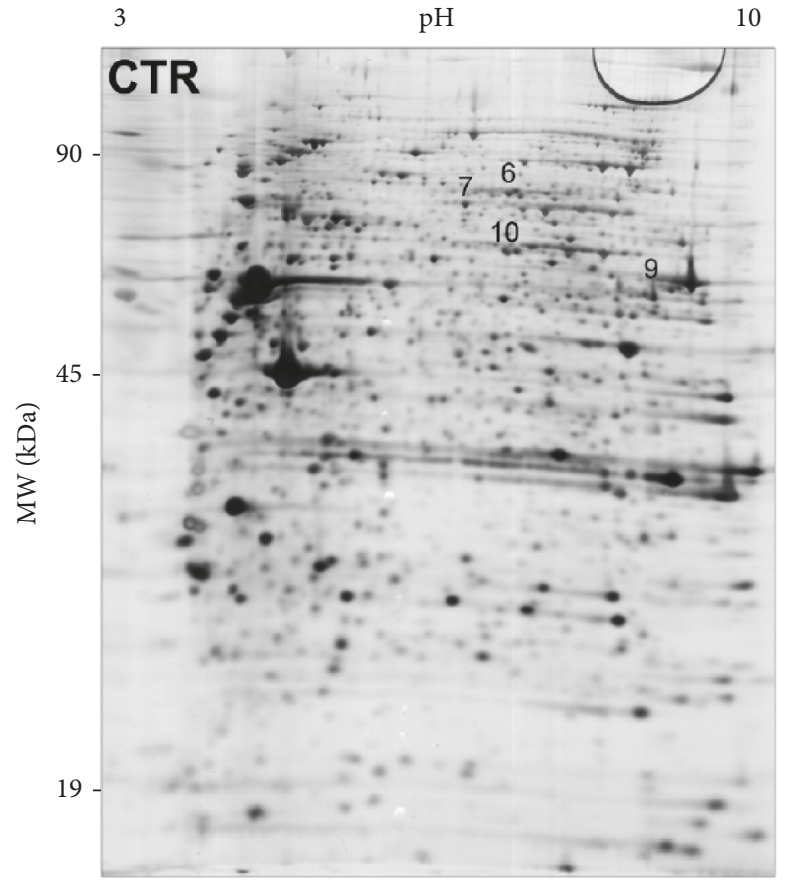

3

$\mathrm{pH}$

10

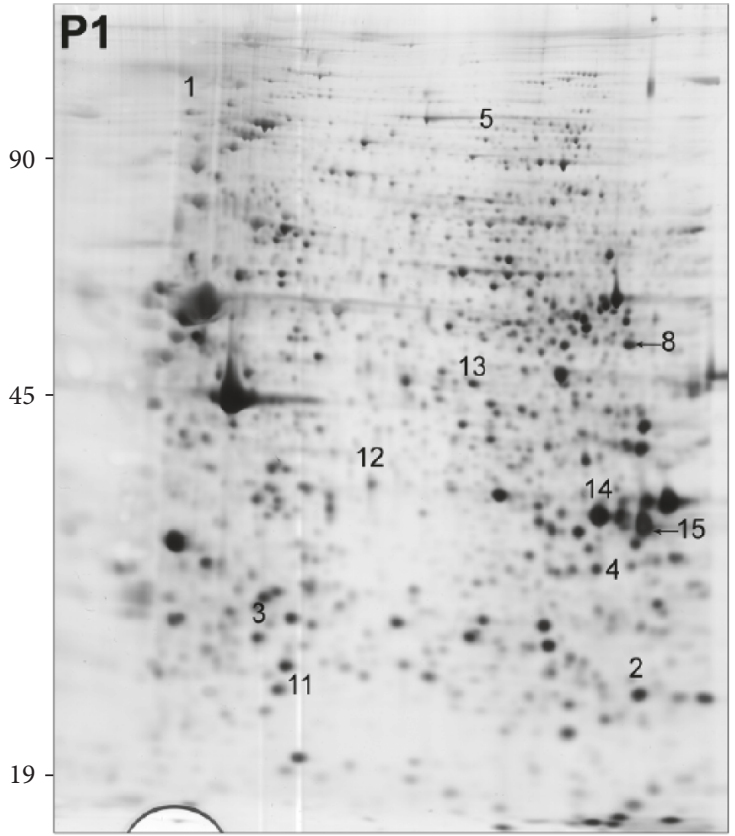

(a)

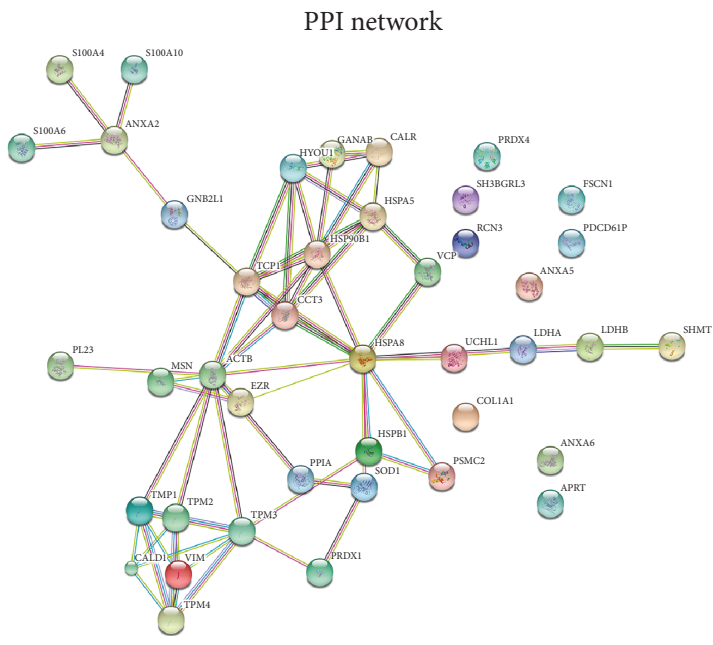

(b)
Protein processing in the endoplamic reticulum

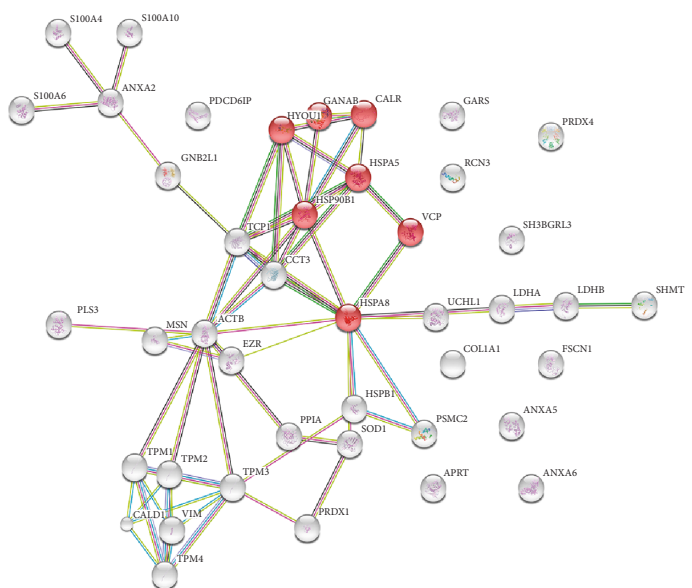

(c)

FIGURE 1: Representative 2-DE gel map of proteins isolated from human CTR and P1 fibroblasts. (a) A total of $80 \mu \mathrm{g}$ of proteins were separated by 2-DE using a $13 \mathrm{~cm}$ IPG strip pH 3-10 NL and 12\% SDS-PAGE. Proteins were visualized by silver staining. Spot numbers indicate proteins that were differentially regulated between CTR and P1 samples. (b, c) Bioinformatics analysis of differentially expressed proteins. (b) A high confidence protein-protein interaction network generated with STRING using our protein dataset is shown. The network nodes are input proteins. The edges represent the predicted functional associations. An edge may be drawn with up to 7 differently colored lines-these lines represent the existence of the seven types of evidence used in predicting the associations. A red line indicates the presence of fusion evidence; a green line, neighborhood evidence; a blue line, coocurrence evidence; a purple line, experimental evidence; a yellow line, textmining evidence; a light blue line, database evidence; and a black line, coexpression evidence. (c) Proteins involved in protein processing in the endoplasmic reticulum proteins are highlighted in red (HYOU1, GANAB, CALR, HSPA5, HSP90B1, VCP, and HSPA8) in the main PPI network.

including Alzheimer's disease and PD [42, 43]. Protein folding in the ER is finely regulated by various conditions including redox state and calcium concentrations. In the list of the molecular functions (Table 3), we observed that the calcium ion binding and unfolded protein binding pathways were significantly enriched in CTR versus $\mathrm{P} 1$ cells suggesting that the defect of these functions in P1 cells could be responsible for the altered cellular homeostasis. Furthermore, according to our previous work $[17,34]$, we detected in PD samples with respect to CTR a significantly lower level of the protein 

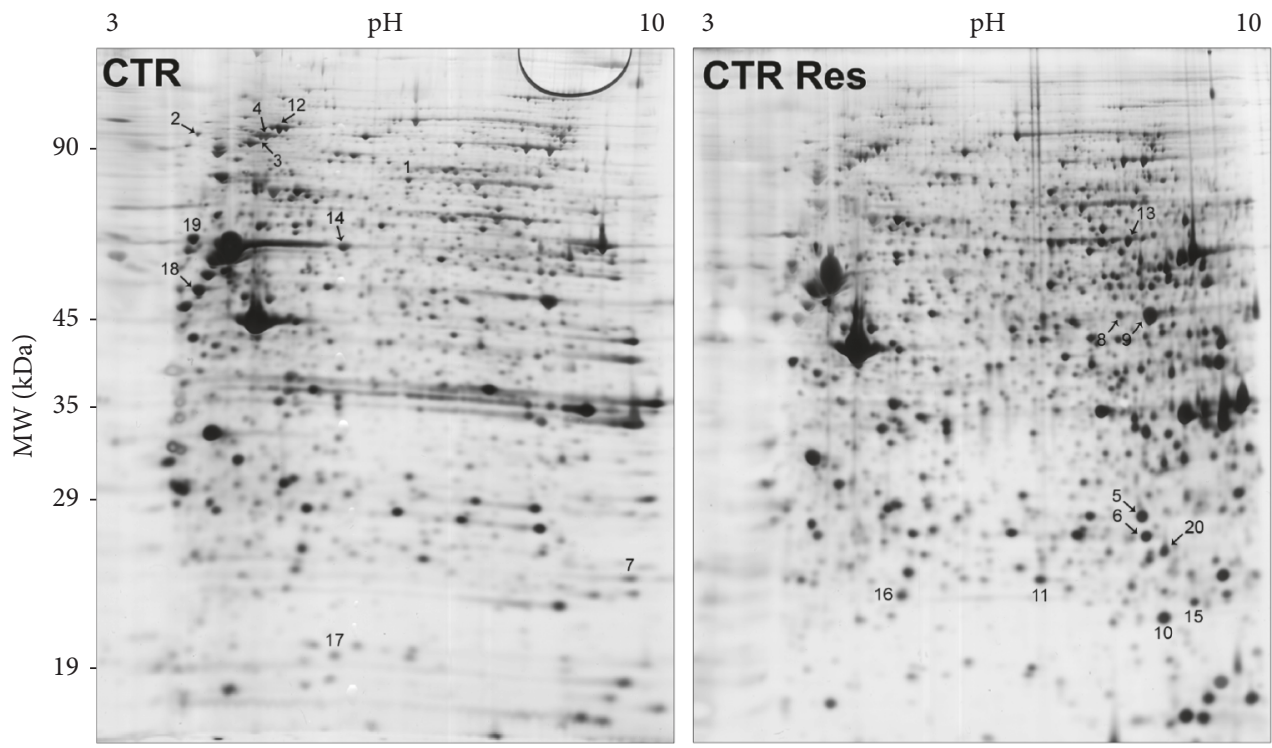

FIGURE 2: Representative 2-DE gel map of CTR and CTR-Res-treated cell proteins. A total of $80 \mu \mathrm{g}$ of proteins were separated by 2-DE using a $13 \mathrm{~cm}$ IPG strip pH3-10 NL and 12\% SDS-PAGE. Proteins were visualized by silver staining. Spot numbers indicate differentially expressed proteins.
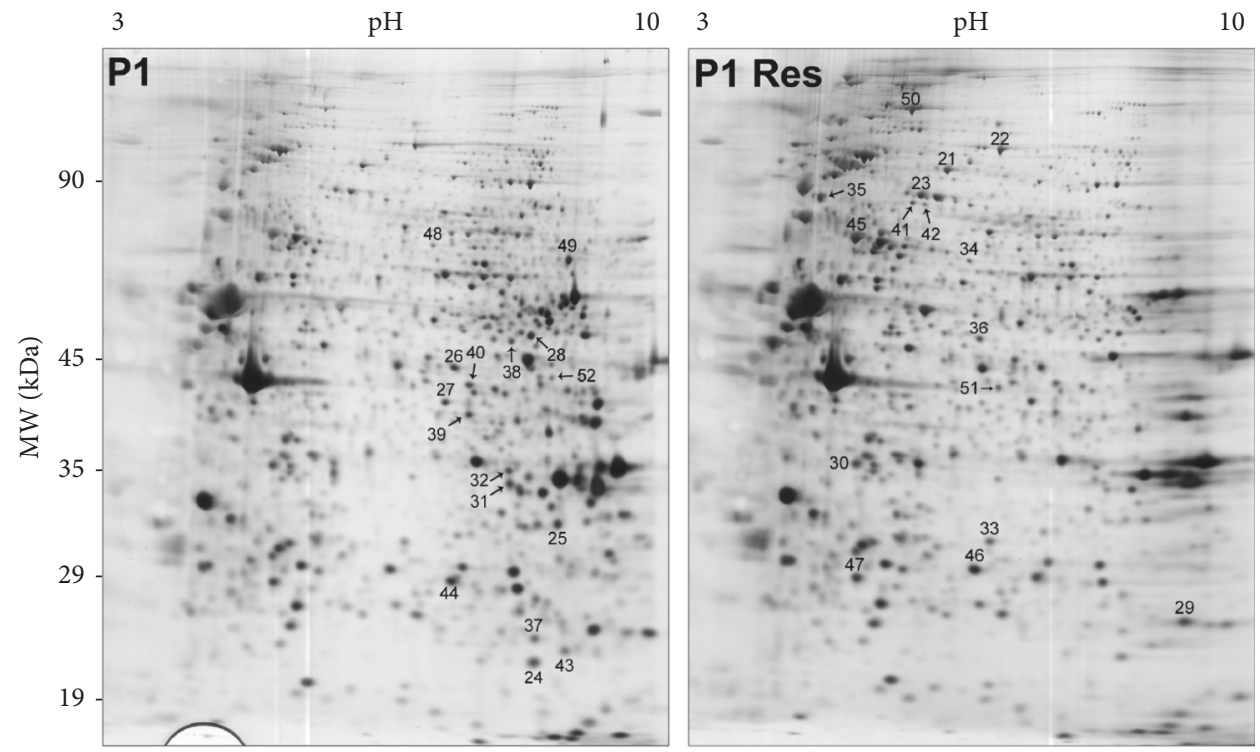

Figure 3: Representative 2-DE gel map of P1 and P1-Res-treated cell proteins. A total of $80 \mu \mathrm{g}$ of proteins were separated by 2 -DE using a $13 \mathrm{~cm}$ IPG strip pH 3-10 NL and 12\% SDS-PAGE. Proteins were visualized by silver staining. Spot numbers indicate differentially expressed proteins.

ezrin, a member of the ERM (ezrin, radixin, and moesin) protein family, involved in the connection of major cytoskeletal structures to the plasma membrane [44].

Overall these new data, together with the previously obtained results, point to the involvement of parkin in the regulation of a complex network of processes related to cytoskeletal rearrangements and protein folding organization in the ER $[17,34]$.

3.2. Establishing a Proteomic Expression Signature Associated with Resveratrol Treatment in Control and PD Fibroblasts.
Since in vitro and in vivo studies demonstrated the promising effects of resveratrol on neuronal diseases, with a welldescribed effect in retarding or even reversing the accelerated rate of neuronal degeneration $[25-27,45,46]$, we went through the study of protein expression profile in a cellular PD model to gain further insights into the molecular effects induced by resveratrol treatment.

Protein expression was investigated by 2-DE and MALDI-MS/MS analysis after $24 \mathrm{~h}$ of treatment with resveratrol at the concentration of $25 \mu \mathrm{M}$ or with vehicle (DMSO) (Figures 2 and 3). A specific dataset of proteins resulted 


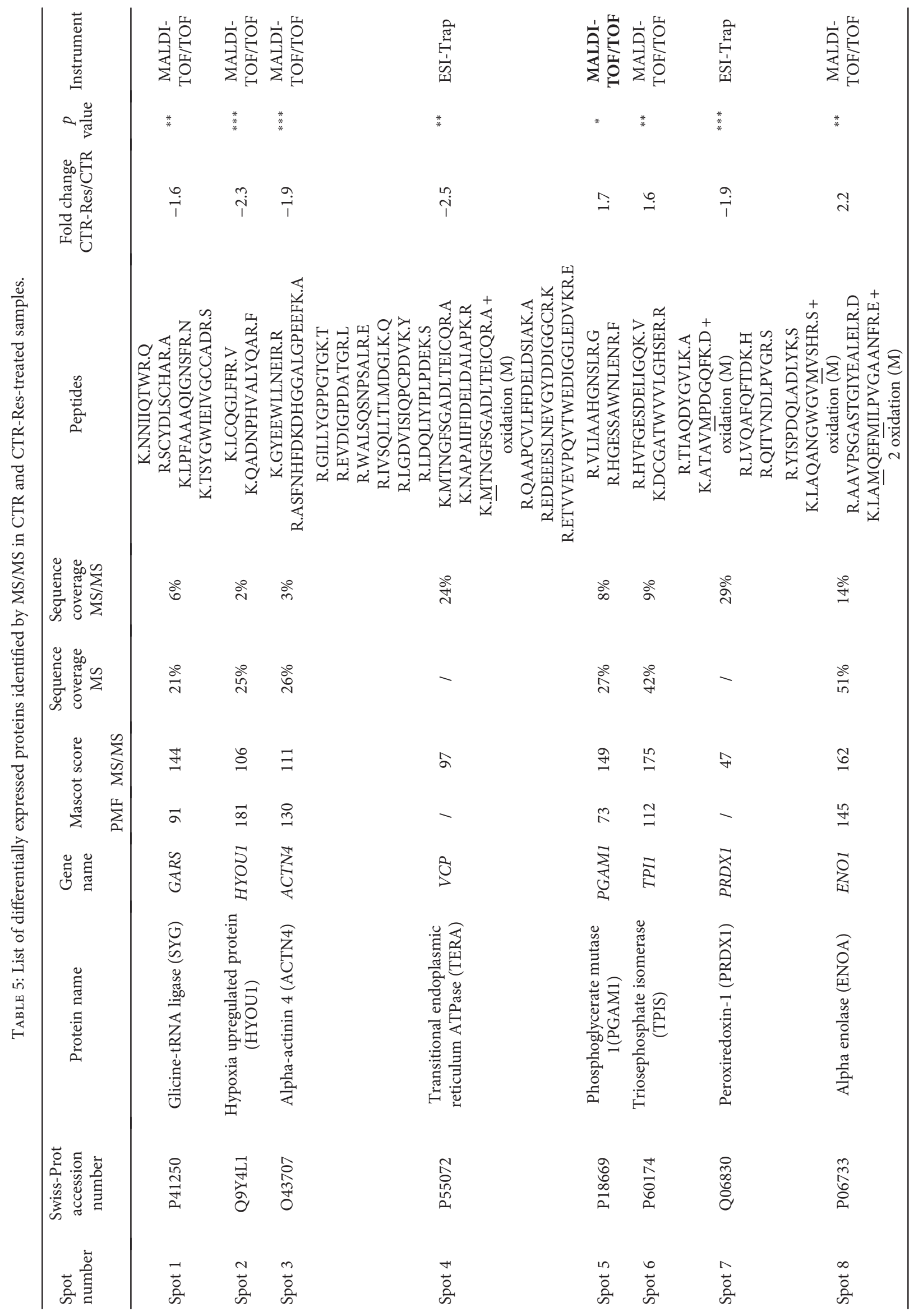




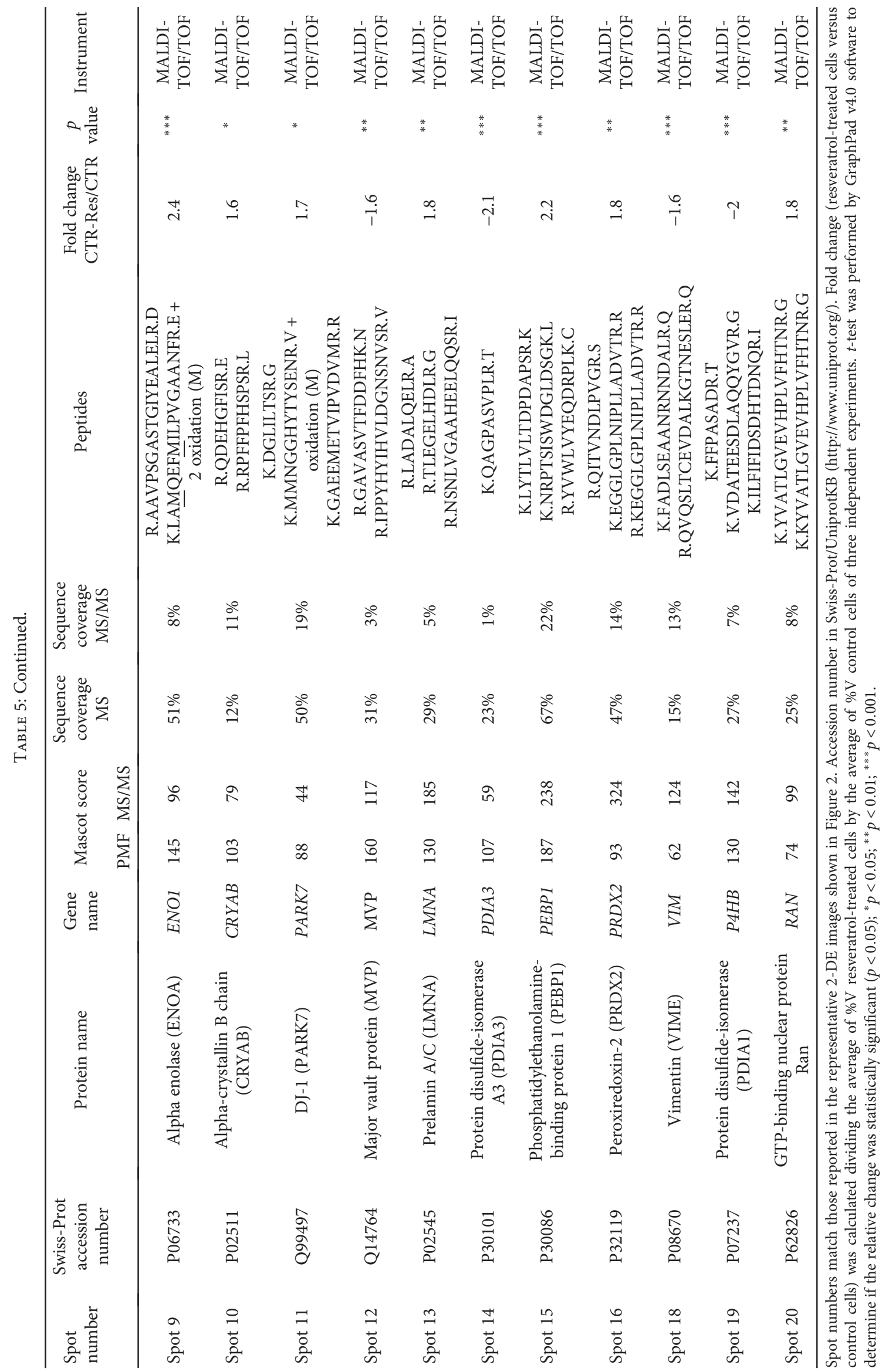




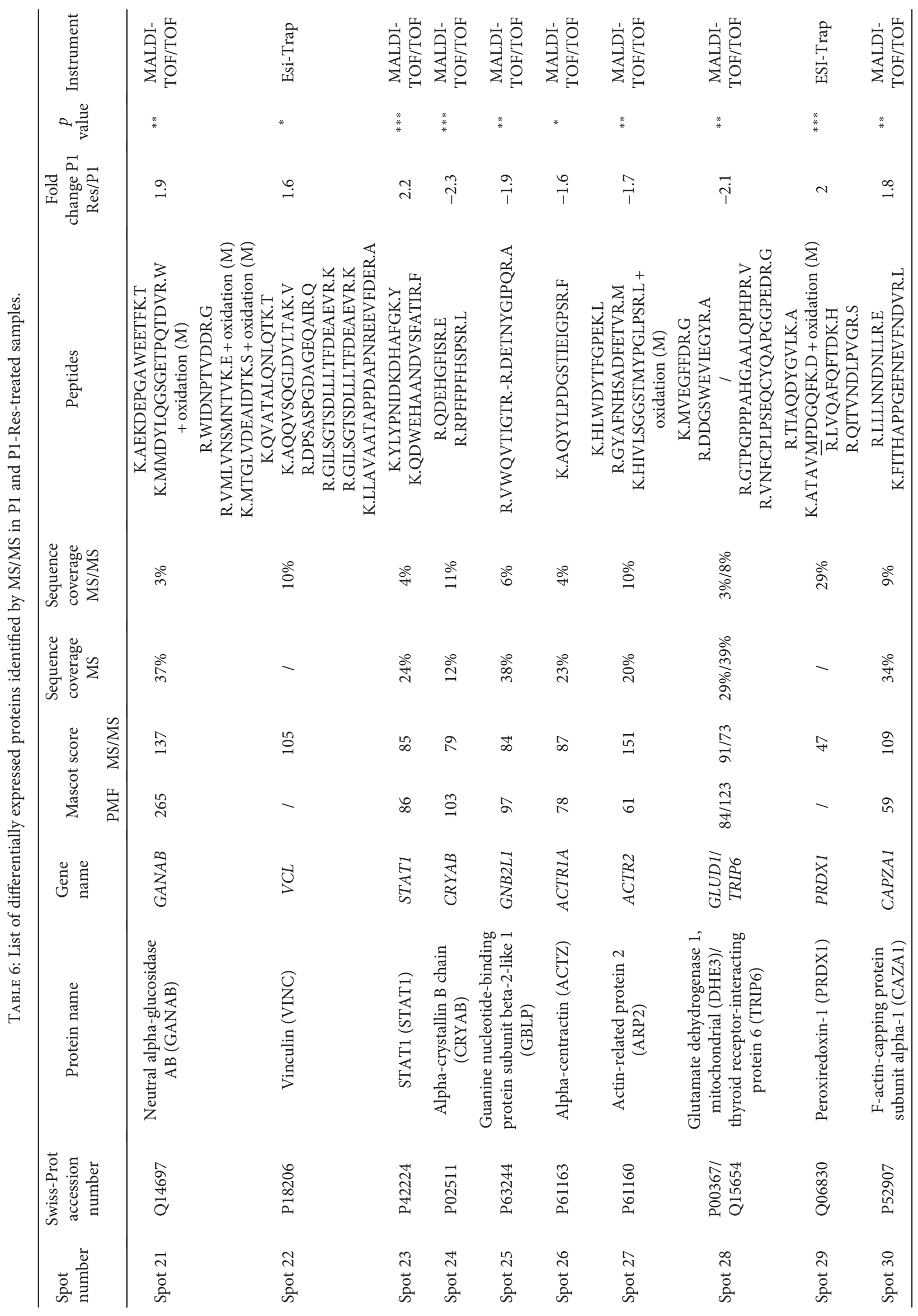




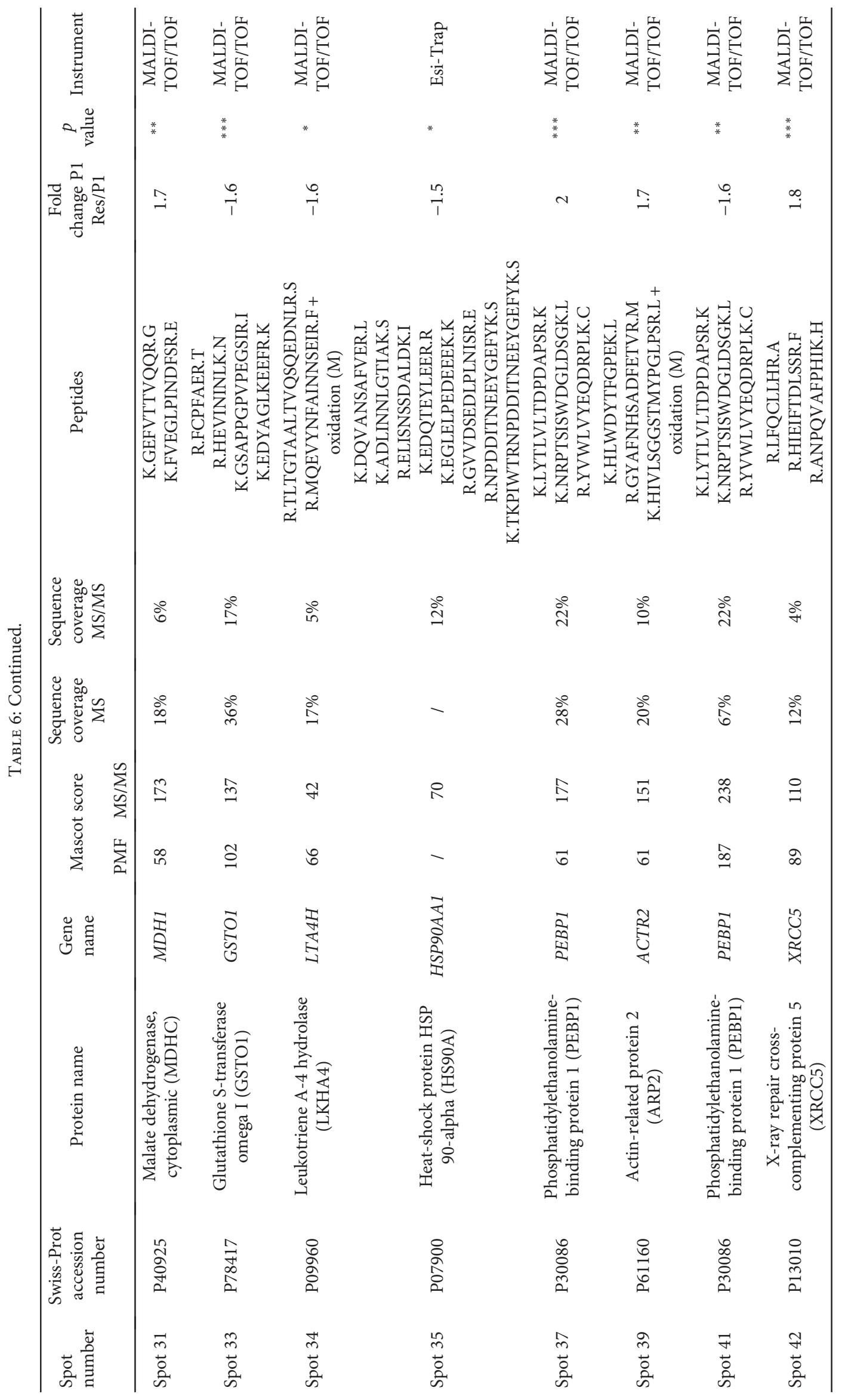




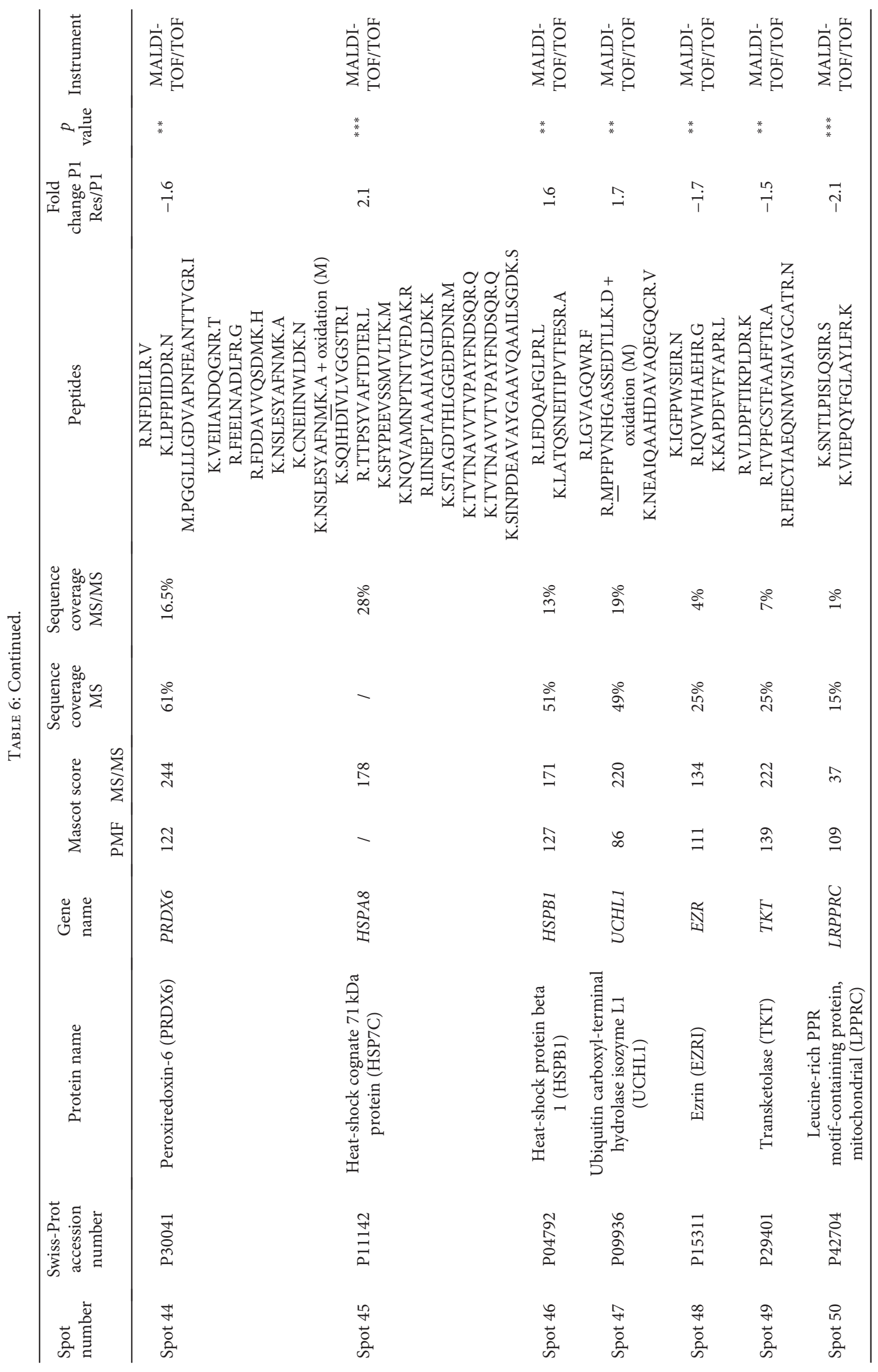




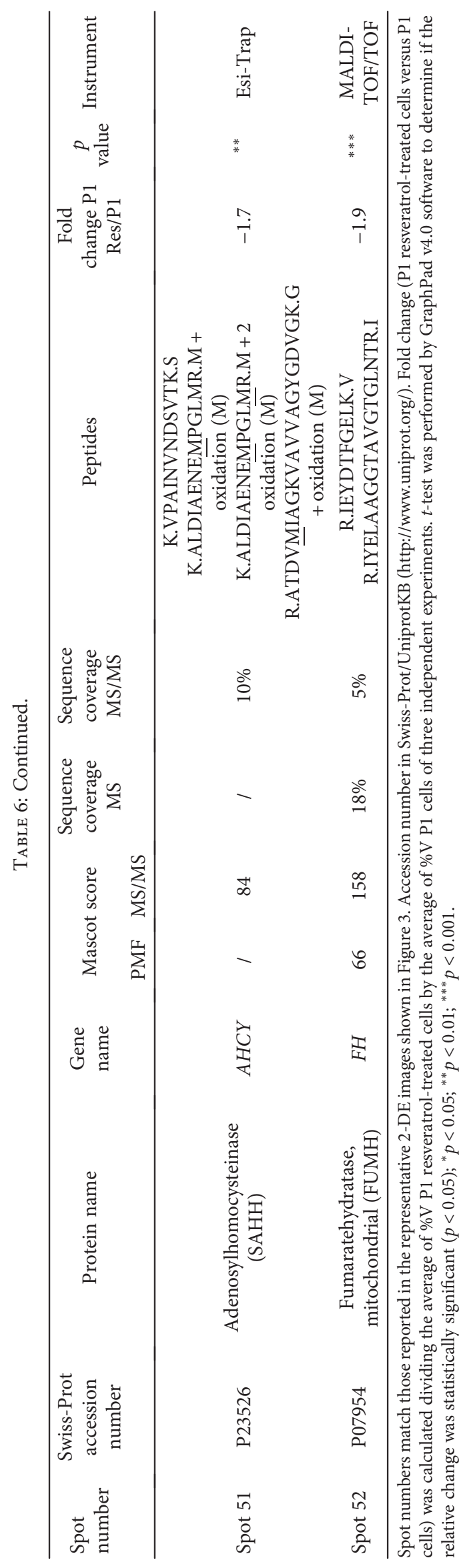


TABLE 7: List of significantly enriched biological processes in CTR versus CTR-Res protein dataset identified by STRING software.

\begin{tabular}{lccc}
\hline $\begin{array}{l}\text { Biological process }(\mathrm{GO}) \\
\text { Pathway ID }\end{array}$ & Pathway description & Count in gene set & False discovery rate \\
\hline GO:0001666 & Response to hypoxia & 5 & 0.00305 \\
GO:0034976 & Response to endoplasmic reticulum stress & 5 & 0.00305 \\
GO:0042743 & Hydrogen peroxide metabolic process & 3 & 0.00305 \\
GO:0061621 & Canonical glycolysis & 3 & 0.00305 \\
GO:2000152 & Regulation of ubiquitin-specific protease activity & 2 & 0.00305 \\
\hline
\end{tabular}

TABLE 8: List of significantly enriched molecular functions in CTR versus CTR-Res protein dataset identified by STRING software.

\begin{tabular}{lccc}
\hline $\begin{array}{l}\text { Molecular function }(\mathrm{GO}) \\
\text { Pathway ID }\end{array}$ & Pathway description & Count in gene set & False discovery rate \\
\hline GO:0051920 & Peroxiredoxin activity & 3 & $8.22 e-05$ \\
GO:0003723 & RNA binding & 10 & 0.000179 \\
GO:0044822 & Poly(A) RNA binding & 9 & 0.000179 \\
GO:0005515 & Protein binding & 13 & 0.00361 \\
GO:0008379 & Thioredoxin peroxidase activity & 2 & 0.00361 \\
\hline
\end{tabular}

TABLE 9: List of significantly enriched molecular functions in P1 versus P1-Res protein dataset identified by STRING software.

\begin{tabular}{lccc}
\hline $\begin{array}{l}\text { Molecular function }(\mathrm{GO}) \\
\text { Pathway ID }\end{array}$ & Pathway description & Count in gene set & 11 \\
\hline GO:0019899 & Enzyme binding & 6 & 0.000172 \\
GO:0031625 & Ubiquitin protein ligase binding & 10 & 0.000172 \\
GO:0044822 & Poly(A) RNA binding & 15 & 0.000228 \\
GO:0005515 & Protein binding & 2 & 0.00801 \\
GO:0051920 & Peroxiredoxin activity & 0.0162 \\
\hline
\end{tabular}

differentially expressed in CTR and P1 fibroblasts and listed in Tables 5 and 6. These datasets were functionally annotated using the software STRING. The most enriched GO terms of molecular functions and biological processes are depicted in Tables 7, 8, and 9. After resveratrol treatment, CTR fibroblasts showed changes in the protein level associated with peroxiredoxin activity (Table 8). This is in line with previous observations that linked resveratrol action with the modulation of enzymes involved in the ROS metabolism [28, 47]. The effect of resveratrol treatment on proteins with peroxiredoxin activity was also observed, to a lesser extent, in P1 fibroblasts (Table 9). These results were validated by Western blotting analysis (Figure 4). Consistent with MS data, P1 resveratrol-treated cells expressed higher levels of PXR1 and lower levels of PXR6 compared to untreated cells. By contrast, CTR cells showed a trend towards a lower PXR1 and higher PXR6 expression in resveratroltreated cells compared to untreated cells.

3.3. Modulation of Redox Status of Sulfhydryl Groups upon Treatment with Resveratrol. Mammalian cells have a welldefined set of antioxidant enzymes, which includes superoxide dismutase, catalase, glutathione peroxidases, and peroxiredoxins, ubiquitous enzymes that have emerged as an important and widespread peroxide and peroxynitrite scavenging system [48]. PD is characterized by changes in oxidative balance, and the loss of glutathione (GSH) level is one of the earliest biochemical changes detectable in PD [49]. GSH is a major component of cellular antioxidant system, whose reduced and oxidized forms (GSH and GSSG) act in concert with other redox-active compounds (e.g., $\mathrm{NAD}(\mathrm{P}) \mathrm{H})$ to regulate and maintain cellular redox status [50]. Glutathione depletion may occur as a defect of its synthesis, as well as its metabolism, when the redox state of the cells is altered. In these conditions, the GSSG produced can be reduced back to GSH, but the formation and export of GSH conjugates could lead to GSH depletion. As shown in Figure 5, total GSH level was significantly lower in P1 fibroblasts as compared to CTR cells (Figure 5(a)). However, treatment of P1 cells with $25 \mu \mathrm{M}$ Res for $24 \mathrm{~h}$ resulted in a significant increase of GSH content (Figure 5(c)), whereas the treatment had no effect on the GSH level in CTR cells (Figure 5(b)). The analysis of oxidized glutathione (GSSG) revealed an increase of GSSG/GSH ratio in P1 cells (Figure 5(d)), which was partially reversed after resveratrol treatment, though the value 


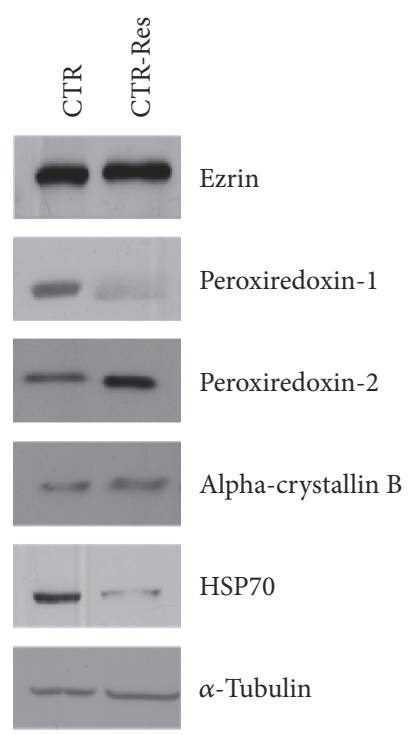

(a)

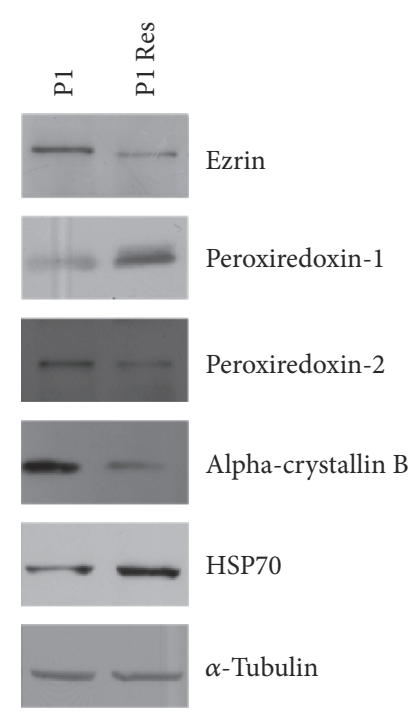

(b)

FIgure 4: Western blot analysis of CTR and P1 fibroblasts treated with resveratrol. CTR and P1 cells were treated with resveratrol at the concentration of $25 \mu \mathrm{M}$ for $24 \mathrm{~h}$. Proteins were separated by SDS-PAGE and probed with the following antibodies: ezrin (1:2000, Santa Cruz, sc-20773), alpha B crystallin (1:1000, Proteintech, 15808-1-AP), peroredoxin-1 (1:2000, Santa Cruz, sc-7381), peroredoxin-2 (1:2000, Santa Cruz, sc-33572), peroredoxin-6 (1:2000, Santa Cruz, sc-393024), and heat-shock protein (HSP70) (1:2000, Sigma, H51747). $\alpha$-Tubulin was used as loading control ( $1: 4000$, Santa Cruz, sc-23948). This image is representative of three independent experiments.

did not reach a statistical significance $(p=0.06)$ (Figure 5(f)). These data are consistent with the observation that resveratrol could act positively on glutathione homeostasis by increasing the activity and the expression, through NRF2, of glutamate cysteine ligase (GCL), the rate-limiting enzyme for de novo GSH synthesis that catalyzes the formation of $\gamma$-glutamylcysteine [51, 52].

Changes in GSH metabolism prompted us to investigate the redox state of thiol groups of protein (P-SH). The thiol groups of the protein are characterized by a reversible formation of a mixed disulfide bond between two cysteines and with glutathione (glutathionylation), which controls correct protein folding and represents an emergent mechanism of posttranslational modification to regulate signal transduction [53]. Quantitative analysis of free sulfhydryl groups of protein $(\mathrm{P}-\mathrm{SH})$ in total cellular lysate reveals higher levels of $\mathrm{P}-\mathrm{SH}$ in $\mathrm{P} 1$ cells respect to CTR cells (Figure 6(a)), and this result could reflect the high steady-state cellular redox state $\left(\mathrm{NADH} / \mathrm{NAD}^{+}\right)$measured in these cells [28]. As expected, resveratrol treatment of CTR cells results in a significant increase of P-SH (Figure 6(b)), reflecting the antioxidant capacity of the employed polyphenol [54]. The P-SH increase could be potentially related to the decreased level of two disulfide isomerases, PDIA3 and $\mathrm{P} 4 \mathrm{HB}$, as detected by the proteomic analysis (Table 6). These proteins check the oxidation (formation), reduction (break down), and isomerization (rearrangement) of protein disulfide bonds via disulfide interchange activity. PDIs also have a chaperone activity by binding to misfolded proteins to prevent them from aggregating and targeting misfolded proteins for degradation [55].

Interestingly, treatment of $\mathrm{P} 1$ cells with resveratrol resulted in the decrease of $\mathrm{P}-\mathrm{SH}$ content reflecting the resveratrol enhancement, in an AMPK-dependent manner, of the
$\mathrm{NAD}^{+} / \mathrm{NADH}$ ratio [28], capable of restoring the basal level of CTR fibroblasts (Figure 6(c)).

Therefore, while the antioxidant effects of resveratrol are predominant in the CTR cells $[22,26]$ the capacity of this natural compound to modulate additional pathways is more evident in P1 cells $[28,51]$, including those regulating the glutathionylation status of proteins.

The redox state of thiol groups is related to glutathionylation of proteins which occurs in unstressed cells under physiological conditions as well as during cellular redox defense [56]. The glutathionylation is either a spontaneous or enzymatically driven finely controlled reversible process, which can involve both the GSH and GSSG [57]. To investigate the modifications in protein glutathionylated residues (PSSG), whole proteins were separated under nonreducing conditions. Western blotting analysis with an antibody against glutathionylated residues revealed, as expected, many protein bands (Figure 6(d)). Densitometric analysis showed a lower level of proteins detected by anti-GSH antibody in P1 cells compared to CTR cells (Figure 6(e)). Furthermore, resveratrol treatment resulted in a decrease of bands detected in control cells and, on the contrary, in an increase of bands detected in P1 cells (Figure 6(e)). These results (Figures 6(d) and 6(e)) are in agreement with the specific changes in $\mathrm{P}-\mathrm{SH}$ levels (Figures 6(a), 6(b), and 6(c)), considering that a P-SH increase corresponds to a P-SSG decrease. Many enzymes are involved in the balance of the redox state of the $\mathrm{SH}$ groups, among which glutathione transferases (GST) catalyze protein glutathionylation [58]. Proteomic analysis reveals that resveratrol treatment of $\mathrm{P} 1$ cells leads to an increase of the glutathione S-transferase omega I (GSTO1) expression (Table 6), a protein possibly responsible for reversing the deregulation of GSH system and the redox state 


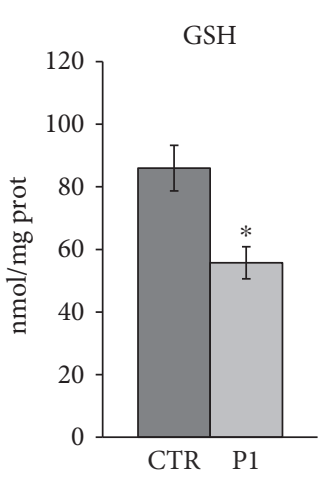

(a)

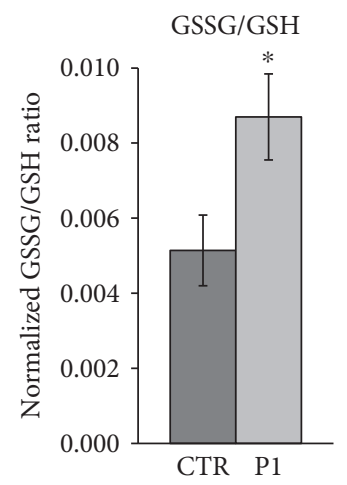

(d)

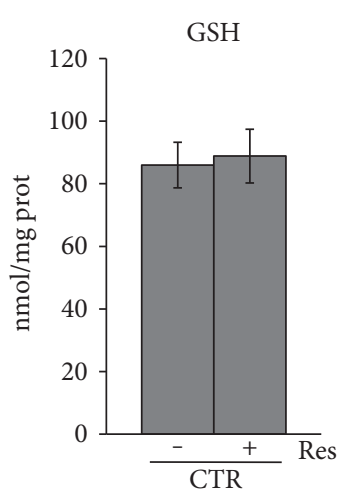

(b)

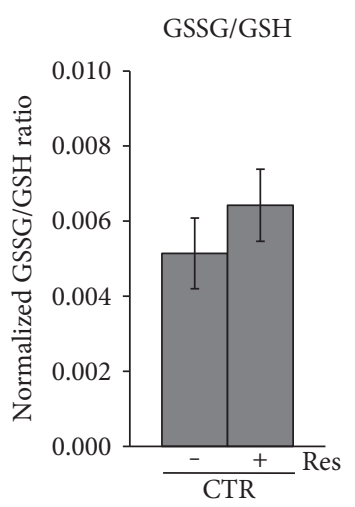

(e)

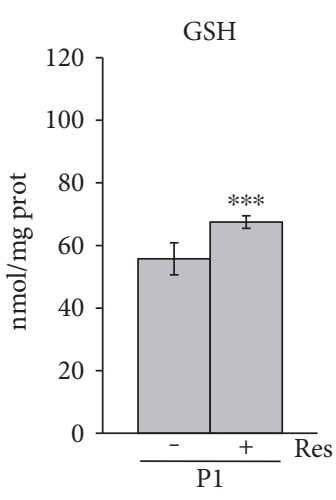

(c)

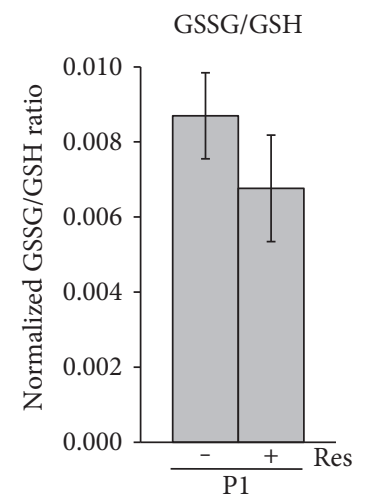

(f)

FIGURE 5: Effect of resveratrol treatment on GSH and GSSG content in patient and control cells. Primary fibroblasts from patient (P1) and control fibroblasts (CTR) were grown as specified in Materials and Methods. As indicated, cells were incubated with $25 \mu \mathrm{M}$ resveratrol for 24 hours (Res). GSH and GSSG content were determined in total cellular lysate. (a) The histogram represents the mean values of GSH basal level \pm SEM of different experiments $(n=3)$. (b, c) Effect of Res treatment on GSH content in CTR and P1 cells. The values are means \pm SEM of different experiments $(n=3)$. (d) The histogram represents the mean values of normalized GSSG/GSH ratio \pm SEM of different experiments $(n=3)$. (e, f) Effect of Res treatment on GSSG/GSH ratio in CTR and P1 cells. The values are means \pm SEM of different experiments $(n=3)$. $p$ value was determined by Student's $t$-test, ${ }^{*} p<0.05,{ }^{* * *} p<0.001$.

of protein sulfhydryl groups. In a Drosophila model of PD, upregulation of Drosophila melanogaster GST Sigma 1 (DmGSTO1) suppressed phenotypes caused by parkin loss of function, including the degeneration of DA neurons and muscle [59].

Deglutathionylation is catalyzed by thiol-disulfide oxidoreductase enzymes, such as glutaredoxin (GRX), thioredoxin (Trx), and protein disulfide isomerase (PDI). PRXs are also involved in the control of protein glutathionylation. Their primary role is associated to $\mathrm{H}_{2} \mathrm{O}_{2}$ detoxification, a process in which the active cysteines of PRX are oxidized. The recycling step of PRX involves the reduction of the disulfide bridge by the thioredoxin system, utilizing NADPH as a source of reducing power [60].

Overall, these data suggest that in P1 cells, there is a deregulation of GSH homeostasis and consequently of the redox state of sulfhydryl groups. The low availability of GSH and deregulation of protein folding processes in the ER, the first intracellular compartment for protein processing such as disulfide bond formation [61], could explain the high level of $\mathrm{P}-\mathrm{SH}$ and the low level of glutathionylated protein observed P1 cells. In our previous study, proteomic analysis revealed a low level of PRDX4 [17], an ER-resident protein, in P1 compared to CTR cells. In the present study, a higher level of PRDX1, a cytosolic protein with antioxidant properties [62], was detected in P1 compared to CTR cells. Both peroxidases use thioredoxin as physiological reductant [48]. Resveratrol treatment restored GSH level and induced normal homeostasis of protein thiol groups in P1 cells. Moreover, in P1 cells, resveratrol treatment induced an upregulation of PRX1 and a downregulation of PRDX6, which uses glutathione as the physiological reductant, saving the amount of the glutathione for other activities.

3.4. Modulation of Chaperone Proteins upon Treatment with Resveratrol. Resveratrol, apart from being an effective scavenger of free radicals, may directly stimulate the cell defense against stress response through cellular chaperone in early time treatment [63]. Some members of the HSPs are differentially expressed in CTR and P1 samples after resveratrol treatment (Tables 5 and 6). Recently, many studies provided evidence that AMPK is a key mediator of the metabolic benefits produced by resveratrol, upstream of SIRT1 activation [64-67]. In the PD cellular model used in our previous study, we have shown that resveratrol regulates energy homeostasis through activation of AMPK and SIRT1 and raises mRNA 


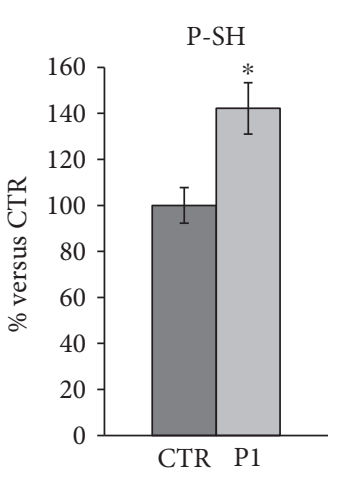

(a)

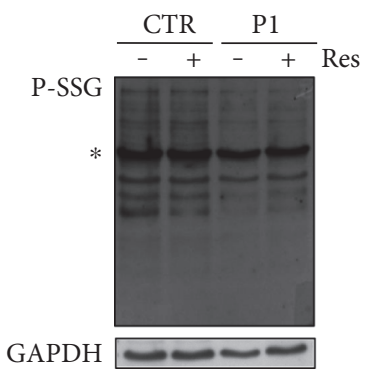

(d)

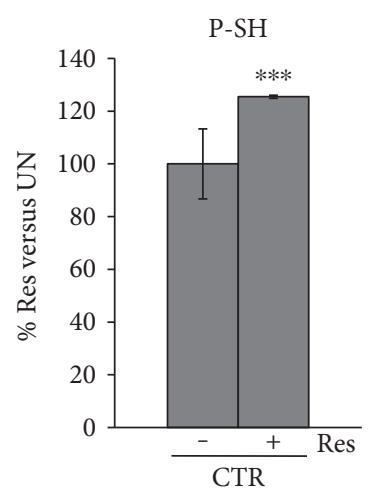

(b)
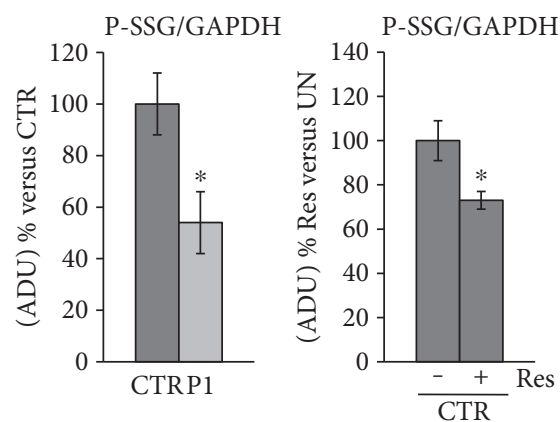

(e)

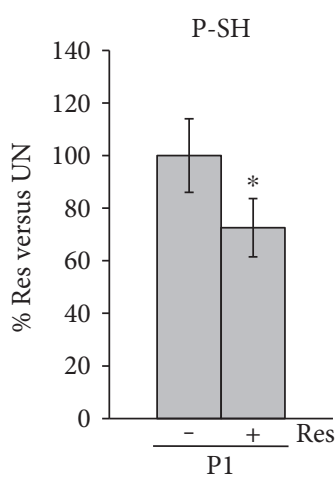

(c)

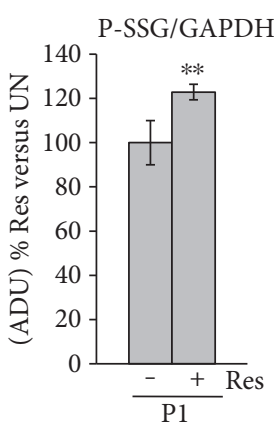

Figure 6: Effect of resveratrol treatment on free thiol groups (P-SH) of protein and glutathionylation in patient and control cells. Primary fibroblasts from patient (P1) and control fibroblasts (CTR) were grown as specified in Materials and Methods. As indicated, cells were incubated with $25 \mu \mathrm{M}$ resveratrol for 24 hours (Res). The P-SH levels were measured in total cellular lysate. (a) The histogram represents the percentage changes with respect to P-SH content of CTR. (b, c) The histograms represent the percentage changes with respect to P-SH content of CTR and P1 untreated cells $(\mathrm{UN})$. ( $\mathrm{a}, \mathrm{b}, \mathrm{c})$ The values are means \pm SEM of different experiments $(n=3)$. (d) A representative image of glutathionylated proteins. Proteins of cellular lysate were loaded on $12 \%$ SDS-PAGE, under nonreducing conditions, transferred to nitrocellulose membranes, and immunoblotted with the antibody against GSH (P-SSG). Protein loading was assessed with the GAPDH antibody. (e) Densitometric analysis of PSSG proteins, normalized to GAPDH, was performed considering all bands immune-revealed by the GSH antibody, excluding the protein band marked with an asterisk. This band is not specific; it also appears in SDS-PAGE under reducing conditions (data not shown). The histograms represent the percentage changes of ADU express as P-SSG/GAPDH ratio. The values are means \pm SEM of different experiments $(n=3)$. $p$ value determined by Student's $t$-test, ${ }^{*} p<0.05,{ }^{* *} p<0.01,{ }^{* * *} p<0.001$.

expression of a number of PGC-1 $\alpha$ 's target genes resulting in enhanced mitochondrial oxidative function, likely related to a decrease of oxidative stress and to an increase of mitochondrial biogenesis [28]. SIRT1 can deacetylate and activate heat-shock factor 1 (HSF1), which affects transcription of molecular chaperones [68].

In addition to protein refolding or degradation, HSPs also support a specialized autophagy mechanism called chaperone-mediated autophagy (CMA). This is a highly selective and constitutive subtype of autophagy that utilizes chaperone proteins and lysosomal receptors to directly target proteins into the lysosomal lumen for their degradation, under both physiological and pathological conditions to maintain cellular homeostasis [69-73]. There are multiple lines of evidence for the impairment of CMA activity in both familial and sporadic PD [74, 75]. In the CMA process, which is activated after macroautophagy and activation persists for days [76], the heat-shock cognate 70 (Hsc70/HSPA8), a constitutive chaperone, binds target proteins and transports them to the surface of endoplasmic reticulum where it specifically binds to lysosomal receptor protein LAMP-2A and HSP90, an inducible chaperone. Resveratrol treatment of $\mathrm{P} 1$ cells induces increased expression of both HSPA8 and HSP90, possibly leading to CMA. Interestingly, we have shown in our previous study that resveratrol treatment caused an enhanced macroautophagic flux through activation of an LC3-independent pathway [28].

Furthermore, concerning the behaviour of alphacrystallin $B$ chain (CRYAB), which belongs to the chaperone family whose main role is to bind improperly folded proteins to prevent protein aggregation [77], we have found that the treatment with resveratrol increased the expression of CRYAB in CRT cells and, on the contrary, induced a decreased expression in P1 cells, reestablishing the levels of control cells (Tables 5 and 7) (Figure 4).

HSPs are proving to be a therapeutic target in neurodegenerative disorders because the pathogenesis of these diseases is thought to be related to an abnormal increase of unfolded protein response (UPR), failure of UPS, and protein misfolding and/or aggregation [78] and their regulation could be mediated by polyphenols as resveratrol $[79,80]$. 
3.5. Modulation of Metabolic Proteins upon Treatment with Resveratrol. As already described, resveratrol can carry out its functions by activating AMPK, a crucial cellular energy sensor. Once activated, it promotes ATP production by increasing the activity or expression of proteins involved in catabolism while conserving ATP by switching off biosynthetic pathways [81]. A significant number of proteins differentially expressed after resveratrol treatment are involved in energy metabolism pathways. We observed an upregulation of several proteins related to glycolysis in resveratroltreated CTR cells. These include phosphoglycerate mutase 1 (PGAM1), triose phosphate isomerase (TPIS), and alpha enolase (ENOA). A changed rate of glycolysis may affect substrate levels for the tricarboxylic acid cycle and subsequent oxidative phosphorylation, in turn influencing ATP levels. Furthermore, we observed an upregulation of the cytoplasmic isoform of malate dehydrogenase (MDHc) in resveratroltreated P1 cells. MDHc is a metabolic isoform involved in the malate-aspartate shuttle that aids in the transfer of reducing equivalents of NADH into the mitochondria. This is in line with the low steady-state cellular ratio $\mathrm{NADH} / \mathrm{NAD}^{+}$ present in resveratrol-treated $\mathrm{P} 1$ cells, which indicates the enhancement of oxidative capacity attested by the increase in mitochondrial ATP production [28].

All these data confirm and extend our previous observations on the metabolic dysfunction of P1 fibroblasts, which show a deregulation of pathways involved in key cellular processes such as protein folding, protein degradation, and cellular redox balance. The analysis of differentially expressed proteins identified after resveratrol treatment of CTR and P1 cells reveals the great ability of resveratrol to act on protein expression modifying pathway and reversing the molecular defects in P1 fibroblast cells.

\section{Conclusions}

P1 fibroblasts are characterized by a dysregulated expression of proteins linked to biological processes regarding cell movement or subcellular component, assembly and protein folding, calcium ion binding, unfolded protein binding, and redox homeostasis. In this study, we show the biological effects of resveratrol acting through the modulation of the expression of proteins involved in protecting cells from the damaging effects of ROS, in protein refolding or degradation, and, specifically, in chaperone-mediated autophagy.

Overall, the complex proteome alterations shown in this ex vivo model of PD could provide further insights into the pathogenic processes involved in the disease. Importantly, the elucidation of the biomarkers might provide new therapeutic targets for the treatment and prevention of PD. Evidences are emerging to support the potential of small bioactive molecules, as resveratrol, against neurodegenerative disorders, to control and modulate ROS and abnormal protein.

\section{Conflicts of Interest}

The authors declare that they have no conflicts of interest.

\section{Acknowledgments}

This work was supported by local grants of the University of Bari to Tiziana Cocco, by FIR 2015-2018 H6SH8W9 from Apulia Region to Consiglia Pacelli, by FIRB-MERIT 2008 no. RBNE08HWLZ012 to Marco Di Paola, and by the National Operational Programme for Research and Competitiveness (PONREC) 'RINOVATIS' (PON02_00563_3448479) to Michele Maffia. The authors gratefully acknowledge funding from the Apulia Regional Cluster project "SISTEMA" project code T7WGSJ3.

\section{References}

[1] L. Hirsch, N. Jette, A. Frolkis, T. Steeves, and T. Pringsheim, "The incidence of Parkinson's disease: a systematic review and meta-analysis," Neuroepidemiology, vol. 46, no. 4, pp. 292-300, 2016.

[2] L. V. Kalia and A. E. Lang, "Parkinson's disease," Lancet (London England), vol. 386, no. 9996, pp. 896-912, 2015.

[3] C. Klein and M. G. Schlossmacher, "The genetics of Parkinson disease: implications for neurological care," Nature Clinical Practice. Neurology, vol. 2, no. 3, pp. 136-146, 2006.

[4] T. Kitada, S. Asakawa, N. Hattori et al., "Mutations in the parkin gene cause autosomal recessive juvenile parkinsonism," Nature, vol. 392, no. 6676, pp. 605-608, 1998.

[5] S. Biskup, M. Gerlach, A. Kupsch et al., "Genes associated with Parkinson syndrome," Journal of Neurology, vol. 255, Supplement 5, pp. 8-17, 2008.

[6] S. Lesage and A. Brice, "Parkinson's disease: from monogenic forms to genetic susceptibility factors," Human Molecular Genetics, vol. 18, no. R1, pp. R48-R59, 2009.

[7] D. Narendra, A. Tanaka, D.-F. Suen, and R. J. Youle, "Parkin is recruited selectively to impaired mitochondria and promotes their autophagy," The Journal of Cell Biology, vol. 183, no. 5, pp. 795-803, 2008.

[8] C. Vives-Bauza, C. Zhou, Y. Huang et al., "PINK1-dependent recruitment of Parkin to mitochondria in mitophagy," Proceedings of the National Academy of Sciences of the United States of America, vol. 107, no. 1, pp. 378-383, 2010.

[9] B. C. Hammerling, R. H. Najor, M. Q. Cortez et al., "A Rab5 endosomal pathway mediates Parkin-dependent mitochondrial clearance," Nature Communications, vol. 8, article 14050, 2017.

[10] J. J. Palacino, D. Sagi, M. S. Goldberg et al., "Mitochondrial dysfunction and oxidative damage in parkin-deficient mice," The Journal of Biological Chemistry, vol. 279, no. 18, pp. 18614-18622, 2004.

[11] N. C. Chan, A. M. Salazar, A. H. Pham et al., "Broad activation of the ubiquitin-proteasome system by Parkin is critical for mitophagy," Human Molecular Genetics, vol. 20, no. 9, pp. 1726-1737, 2011.

[12] N. C. Chan and D. C. Chan, "Parkin uses the UPS to ship off dysfunctional mitochondria," Autophagy, vol. 7, no. 7, pp. 771-772, 2011.

[13] C. Pacelli, D. De Rasmo, A. Signorile et al., "Mitochondrial defect and PGC- $1 \alpha$ dysfunction in parkin-associated familial Parkinson's disease," Biochimica et Biophysica Acta (BBA) - Molecular Basis of Disease, vol. 1812, no. 8, pp. 1041-1053, 2011. 
[14] M. Periquet, O. Corti, S. Jacquier, and A. Brice, "Proteomic analysis of parkin knockout mice: alterations in energy metabolism, protein handling and synaptic function," Journal of Neurochemistry, vol. 95, no. 5, pp. 1259-1276, 2005.

[15] P. G. Unschuld, J. Dächsel, F. Darios et al., "Parkin modulates gene expression in control and ceramide-treated PC12 cells," Molecular Biology Reports, vol. 33, no. 1, pp. 13-32, 2006.

[16] E. J. Davison, K. Pennington, C. C. Hung et al., "Proteomic analysis of increased Parkin expression and its interactants provides evidence for a role in modulation of mitochondrial function," Proteomics, vol. 9, no. 18, pp. 4284-4297, 2009.

[17] R. Lippolis, R. A. Siciliano, C. Pacelli et al., "Altered protein expression pattern in skin fibroblasts from parkin-mutant early-onset Parkinson's disease patients," Biochimica et Biophysica Acta (BBA) - Molecular Basis of Disease, vol. 1852, no. 9, pp. 1960-1970, 2015.

[18] S. Lobasso, P. Tanzarella, D. Vergara, M. Maffia, T. Cocco, and A. Corcelli, "Lipid profiling of parkin-mutant human skin fibroblasts," Journal of Cellular Physiology, vol. 232, no. 12, pp. 3540-3551, 2017.

[19] M. Pallàs, D. Porquet, A. Vicente, and C. Sanfeliu, "Resveratrol: new avenues for a natural compound in neuroprotection," Current Pharmaceutical Design, vol. 19, no. 38, pp. 6726-6731, 2013.

[20] J. Burns, T. Yokota, H. Ashihara, M. E. J. Lean, and A. Crozier, "Plant foods and herbal sources of resveratrol," Journal of Agricultural and Food Chemistry, vol. 50, no. 11, pp. 33373340, 2002.

[21] S. Das and D. K. Das, "Anti-inflammatory responses of resveratrol," Inflammation \& Allergy Drug Targets, vol. 6, no. 3, pp. 168-173, 2007.

[22] M. Kairisalo, A. Bonomo, A. Hyrskyluoto et al., "Resveratrol reduces oxidative stress and cell death and increases mitochondrial antioxidants and XIAP in PC6.3-cells," Neuroscience Letters, vol. 488, no. 3, pp. 263-266, 2011.

[23] J. A. Baur and D. A. Sinclair, "Therapeutic potential of resveratrol: the in vivo evidence," Nature Reviews Drug Discovery, vol. 5, no. 6, pp. 493-506, 2006.

[24] A. Y. Sun, Q. Wang, A. Simonyi, and G. Y. Sun, "Resveratrol as a therapeutic agent for neurodegenerative diseases," Molecular Neurobiology, vol. 41, no. 2-3, pp. 375-383, 2010.

[25] F. Jin, Q. Wu, Y.-F. Lu, Q.-H. Gong, and J.-S. Shi, "Neuroprotective effect of resveratrol on 6-OHDA-induced Parkinson's disease in rats," European Journal of Pharmacology, vol. 600, no. 1-3, pp. 78-82, 2008.

[26] M. M. Khan, A. Ahmad, T. Ishrat et al., "Resveratrol attenuates 6-hydroxydopamine-induced oxidative damage and dopamine depletion in rat model of Parkinson's disease," Brain Research, vol. 1328, pp. 139-151, 2010.

[27] D. D. Lofrumento, G. Nicolardi, A. Cianciulli et al., "Neuroprotective effects of resveratrol in an MPTP mouse model of Parkinson's-like disease: possible role of SOCS-1 in reducing pro-inflammatory responses," Innate Immunity, vol. 20, no. 3, pp. 249-260, 2014.

[28] A. Ferretta, A. Gaballo, P. Tanzarella et al., "Effect of resveratrol on mitochondrial function: implications in parkinassociated familiar Parkinson's disease," Biochimica et Biophysica Acta (BBA) - Molecular Basis of Disease, vol. 1842, no. 7, pp. 902-915, 2014.
[29] D. Vergara, P. Simeone, P. del Boccio et al., "Comparative proteome profiling of breast tumor cell lines by gel electrophoresis and mass spectrometry reveals an epithelial mesenchymal transition associated protein signature," Molecular BioSystems, vol. 9, no. 6, pp. 1127-1138, 2013.

[30] D. Vergara, P. Simeone, D. Latorre et al., "Proteomics analysis of E-cadherin knockdown in epithelial breast cancer cells," Journal of Biotechnology, vol. 202, pp. 3-11, 2015.

[31] D. Vergara, P. Simeone, S. De Matteis et al., "Comparative proteomic profiling of Hodgkin lymphoma cell lines," Molecular BioSystems, vol. 12, no. 1, pp. 219-232, 2016.

[32] M. Chevallet, H. Diemer, S. Luche, A. van Dorsselaer, T. Rabilloud, and E. Leize-Wagner, "Improved mass spectrometry compatibility is afforded by ammoniacal silver staining," Proteomics, vol. 6, no. 8, pp. 2350-2354, 2006.

[33] G. L. Ellman, “Tissue sulfhydryl groups,” Archives of Biochemistry and Biophysics, vol. 82, no. 1, pp. 70-77, 1959.

[34] D. Vergara, M. M. Ferraro, M. Cascione et al., "Cytoskeletal alterations and biomechanical properties of parkin-mutant human primary fibroblasts," Cell Biochemistry and Biophysics, vol. 71, no. 3, pp. 1395-1404, 2015.

[35] R. J. Ellis, "Molecular chaperones: assisting assembly in addition to folding," Trends in Biochemical Sciences, vol. 31, no. 7, pp. 395-401, 2006.

[36] J. Becker and E. A. Craig, "Heat-shock proteins as molecular chaperones," European Journal of Biochemistry, vol. 219, no. 1-2, pp. 11-23, 1994.

[37] K. Richter, M. Haslbeck, and J. Buchner, "The heat shock response: life on the verge of death," Molecular Cell, vol. 40, no. 2, pp. 253-266, 2010.

[38] J. H. Hoffmann, K. Linke, P. C. F. Graf, H. Lilie, and U. Jakob, "Identification of a redox-regulated chaperone network," The EMBO Journal, vol. 23, no. 1, pp. 160-168, 2004.

[39] P. Bishop, D. Rocca, and J. M. Henley, "Ubiquitin C-terminal hydrolase L1 (UCH-L1): structure, distribution and roles in brain function and dysfunction," The Biochemical Journal, vol. 473, no. 16, pp. 2453-2462, 2016.

[40] Z. Liu, S. Hamamichi, B. D. Lee et al., "Inhibitors of LRRK2 kinase attenuate neurodegeneration and Parkinson-like phenotypes in Caenorhabditis elegans and Drosophila Parkinson's disease models," Human Molecular Genetics, vol. 20, no. 20, pp. 3933-3942, 2011.

[41] J. E. McKeon, D. Sha, L. Li, and L.-S. Chin, "Parkin-mediated K63-polyubiquitination targets ubiquitin C-terminal hydrolase L1 for degradation by the autophagy-lysosome system," Cellular and Molecular Life Sciences, vol. 72, no. 9, pp. 18111824, 2015.

[42] S. Matus, L. H. Glimcher, and C. Hetz, "Protein folding stress in neurodegenerative diseases: a glimpse into the ER," Current Opinion in Cell Biology, vol. 23, no. 2, pp. 239-252, 2011.

[43] C. Hetz and B. Mollereau, "Disturbance of endoplasmic reticulum proteostasis in neurodegenerative diseases," Nature Reviews Neuroscience, vol. 15, no. 4, pp. 233-249, 2014.

[44] R. G. Fehon, A. I. McClatchey, and A. Bretscher, "Organizing the cell cortex: the role of ERM proteins," Nature Reviews Molecular Cell Biology, vol. 11, no. 4, pp. 276-287, 2010.

[45] C. Ramassamy, "Emerging role of polyphenolic compounds in the treatment of neurodegenerative diseases: a review of their intracellular targets," European Journal of Pharmacology, vol. 545, no. 1, pp. 51-64, 2006. 
[46] A. Rajeswari and M. Sabesan, "Inhibition of monoamine oxidase- $\mathrm{B}$ by the polyphenolic compound, curcumin and its metabolite tetrahydrocurcumin, in a model of Parkinson's disease induced by MPTP neurodegeneration in mice," Inflammopharmacology, vol. 16, no. 2, pp. 96-99, 2008.

[47] S. S. Leonard, C. Xia, B. H. Jiang et al., "Resveratrol scavenges reactive oxygen species and effects radicalinduced cellular responses," Biochemical and Biophysical Research Communications, vol. 309, no. 4, pp. 10171026, 2003.

[48] P. A. Karplus, "A primer on peroxiredoxin biochemistry," Free Radical Biology \& Medicine, vol. 80, pp. 183-190, 2015.

[49] H. L. Martin and P. Teismann, "Glutathione-a review on its role and significance in Parkinson's disease," The FASEB journal, vol. 23, no. 10, pp. 3263-3272, 2009.

[50] F. Q. Schafer and G. R. Buettner, "Redox environment of the cell as viewed through the redox state of the glutathione disulfide/glutathione couple," Free Radical Biology \& Medicine, vol. 30, no. 11, pp. 1191-1212, 2001.

[51] H. Zhang, A. Shih, A. Rinna, and H. J. Forman, "Resveratrol and 4-hydroxynonenal act in concert to increase glutamate cysteine ligase expression and glutathione in human bronchial epithelial cells," Archives of Biochemistry and Biophysics, vol. 481, no. 1, pp. 110-115, 2009.

[52] C. Chen, X. Jiang, Y. Lai, Y. Liu, and Z. Zhang, "Resveratrol protects against arsenic trioxide-induced oxidative damage through maintenance of glutathione homeostasis and inhibition of apoptotic progression," Environmental and Molecular Mutagenesis, vol. 56, no. 3, pp. 333-346, 2015.

[53] B. G. Hill and A. Bhatnagar, "Protein S-glutathiolation: redox-sensitive regulation of protein function," Journal of Molecular and Cellular Cardiology, vol. 52, no. 3, pp. 559567, 2012.

[54] J. A. Santos, G. S. G. de Carvaho, V. Oliveira, N. R. B. Raposo, and A. D. da Silva, "Resveratrol and analogues: a review of antioxidant activity and applications to human health," Recent Patents on Food, Nutrition \& Agriculture, vol. 5, no. 2, pp. 144153, 2013.

[55] A. M. Benham, "The protein disulfide isomerase family: key players in health and disease," Antioxidants \& Redox Signaling, vol. 16, no. 8, pp. 781-789, 2012.

[56] I. Dalle-Donne, G. Colombo, N. Gagliano et al., "S-glutathiolation in life and death decisions of the cell," Free Radical Research, vol. 45, no. 1, pp. 3-15, 2011.

[57] D. Popov, "Protein S-glutathionylation: from current basics to targeted modifications," Archives of Physiology and Biochemistry, vol. 120, no. 4, pp. 123-130, 2014.

[58] D. M. Townsend, Y. Manevich, L. He, S. Hutchens, C. J. Pazoles, and K. D. Tew, "Novel role for glutathione S-transferase pi. Regulator of protein S-glutathionylation following oxidative and nitrosative stress," The Journal of Biological Chemistry, vol. 284, no. 1, pp. 436-445, 2009.

[59] K. Kim, S.-H. Kim, J. Kim, H. Kim, and J. Yim, "Glutathione s-transferase omega 1 activity is sufficient to suppress neurodegeneration in a Drosophila model of Parkinson disease," The Journal of Biological Chemistry, vol. 287, no. 9, pp. 6628-6641, 2012.

[60] N. P. Hoyle and J. S. O’Neill, "Oxidation-reduction cycles of peroxiredoxin proteins and nontranscriptional aspects of timekeeping," Biochemistry (Mosc), vol. 54, no. 2, pp. 184193, 2015.
[61] D. M. Townsend, "S-glutathionylation: indicator of cell stress and regulator of the unfolded protein response," Molecular Interventions, vol. 7, no. 6, pp. 313-324, 2007.

[62] E.-M. Hanschmann, J. R. Godoy, C. Berndt, C. Hudemann, and C. H. Lillig, "Thioredoxins, glutaredoxins, and peroxiredoxins-molecular mechanisms and health significance: from cofactors to antioxidants to redox signaling," Antioxidants \& Redox Signaling, vol. 19, no. 13, pp. 1539-1605, 2013.

[63] A. Putics, E. M. Végh, P. Csermely, and C. Soti, "Resveratrol induces the heat-shock response and protects human cells from severe heat stress," Antioxidants \& Redox Signaling, vol. 10, no. 1, pp. 65-75, 2008.

[64] J. A. Baur, K. J. Pearson, N. L. Price et al., "Resveratrol improves health and survival of mice on a high-calorie diet," Nature, vol. 444, no. 7117, pp. 337-342, 2006.

[65] C. Cantó and J. Auwerx, "AMP-activated protein kinase and its downstream transcriptional pathways," Cellular and Molecular Life Sciences, vol. 67, no. 20, pp. 3407-3423, 2010.

[66] B. Dasgupta and J. Milbrandt, "Resveratrol stimulates AMP kinase activity in neurons," Proceedings of the National Academy of Sciences of the United States of America, vol. 104, no. 17, pp. 7217-7222, 2007.

[67] C. E. Park, M. J. Kim, J. H. Lee et al., "Resveratrol stimulates glucose transport in $\mathrm{C} 2 \mathrm{C} 12$ myotubes by activating AMPactivated protein kinase," Experimental \& Molecular Medicine, vol. 39, no. 2, pp. 222-229, 2007.

[68] S. D. Westerheide, J. Anckar, S. M. Stevens, L. Sistonen, and R. I. Morimoto, "Stress-inducible regulation of heat shock factor 1 by the deacetylase SIRT1," Science, vol. 323, no. 5917, pp. 1063-1066, 2009.

[69] S. Kaushik and A. M. Cuervo, "Chaperone-mediated autophagy," Methods in Molecular Biology (Clifton, N.J.), vol. 445, pp. 227-244, 2008.

[70] U. Bandyopadhyay, S. Kaushik, L. Varticovski, and A. M. Cuervo, "The chaperone-mediated autophagy receptor organizes in dynamic protein complexes at the lysosomal membrane," Molecular and Cellular Biology, vol. 28, no. 18, pp. 5747-5763, 2008.

[71] A. K. Rout, M.-P. Strub, G. Piszczek, and N. Tjandra, "Structure of transmembrane domain of lysosome-associated membrane protein type 2a (LAMP-2A) reveals key features for substrate specificity in chaperone-mediated autophagy," The Journal of Biological Chemistry, vol. 289, no. 51, pp. 35111-35123, 2014.

[72] R. Kiffin, C. Christian, E. Knecht, and A. M. Cuervo, “Activation of chaperone-mediated autophagy during oxidative stress," Molecular Biology of the Cell, vol. 15, no. 11, pp. 4829-4840, 2004.

[73] A. C. Massey, S. Kaushik, G. Sovak, R. Kiffin, and A. M. Cuervo, "Consequences of the selective blockage of chaperone-mediated autophagy," Proceedings of the National Academy of Sciences of the United States of America, vol. 103, no. 15, pp. 5805-5810, 2006.

[74] L. Alvarez-Erviti, M. C. Rodriguez-Oroz, J. M. Cooper et al., "Chaperone-mediated autophagy markers in Parkinson disease brains," Archives of Neurology, vol. 67, no. 12, pp. 1464$1472,2010$.

[75] K. E. Murphy, A. M. Gysbers, S. K. Abbott et al., "Lysosomalassociated membrane protein 2 isoforms are differentially affected in early Parkinson's disease," Movement Disorders: Official Journal of the Movement Disorder Society, vol. 30, no. 12, pp. 1639-1647, 2015. 
[76] A. M. Cuervo, E. Knecht, S. R. Terlecky, and J. F. Dice, “Activation of a selective pathway of lysosomal proteolysis in rat liver by prolonged starvation," The American Journal of Physiology, vol. 269, no. 5, Part 1, pp. C1200-C1208, 1995.

[77] S. Yamamoto, A. Yamashita, N. Arakaki, H. Nemoto, and T. Yamazaki, "Prevention of aberrant protein aggregation by anchoring the molecular chaperone $\alpha \mathrm{B}$-crystallin to the endoplasmic reticulum," Biochemical and Biophysical Research Communications, vol. 455, no. 3-4, pp. 241-245, 2014.

[78] C. Sõti, E. Nagy, Z. Giricz, L. Vígh, P. Csermely, and P. Ferdinandy, "Heat shock proteins as emerging therapeutic targets," British Journal of Pharmacology, vol. 146, no. 6, pp. 769-780, 2005.

[79] S. Han, J.-R. Choi, K. Soon Shin, and S. J. Kang, "Resveratrol upregulated heat shock proteins and extended the survival of G93A-SOD1 mice," Brain Research, vol. 1483, pp. 112-117, 2012.

[80] M. Currò, A. Trovato-Salinaro, A. Gugliandolo et al., "Resveratrol protects against homocysteine-induced cell damage via cell stress response in neuroblastoma cells," Journal of Neuroscience Research, vol. 93, no. 1, pp. 149-156, 2015.

[81] D. G. Hardie, F. A. Ross, and S. A. Hawley, "AMPK: a nutrient and energy sensor that maintains energy homeostasis," Nature Reviews Molecular Cell Biology, vol. 13, no. 4, pp. 251-262, 2012. 


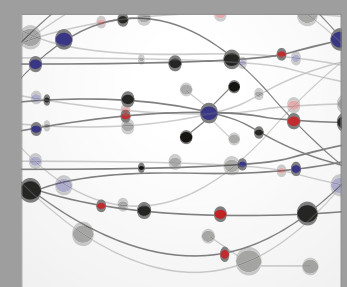

The Scientific World Journal
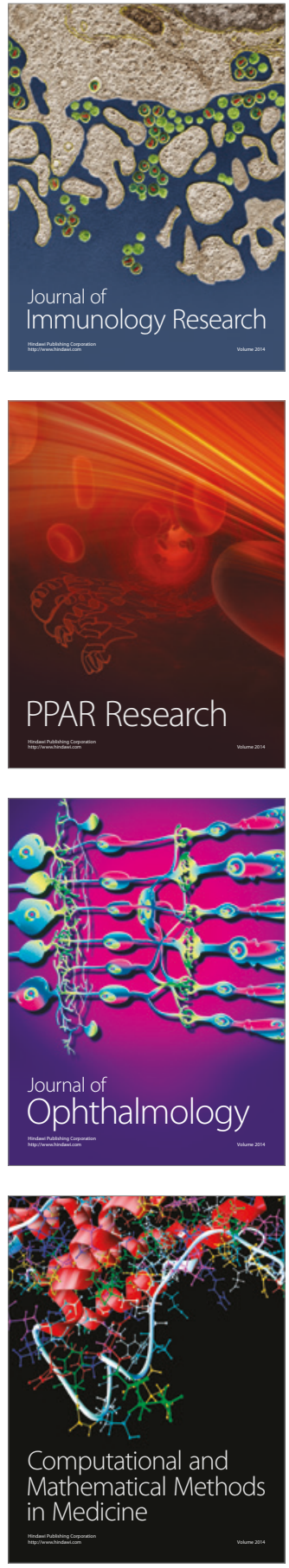

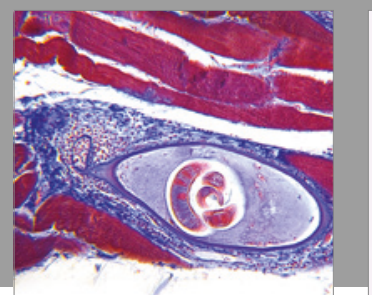

Gastroenterology Research and Practice
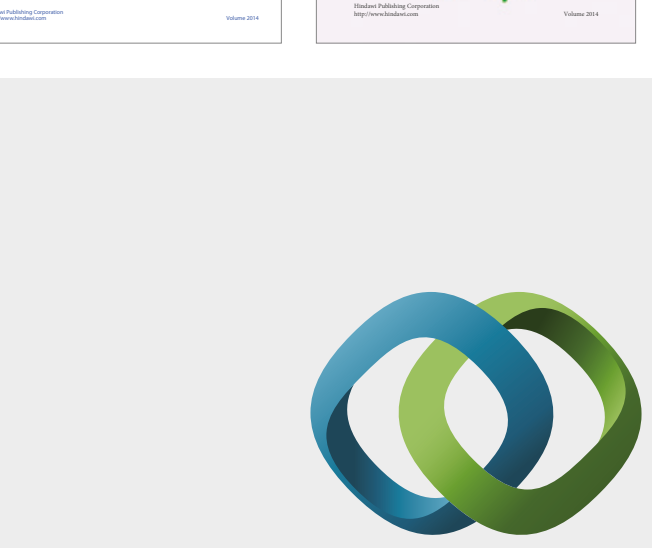

\section{Hindawi}

Submit your manuscripts at

https://www.hindawi.com
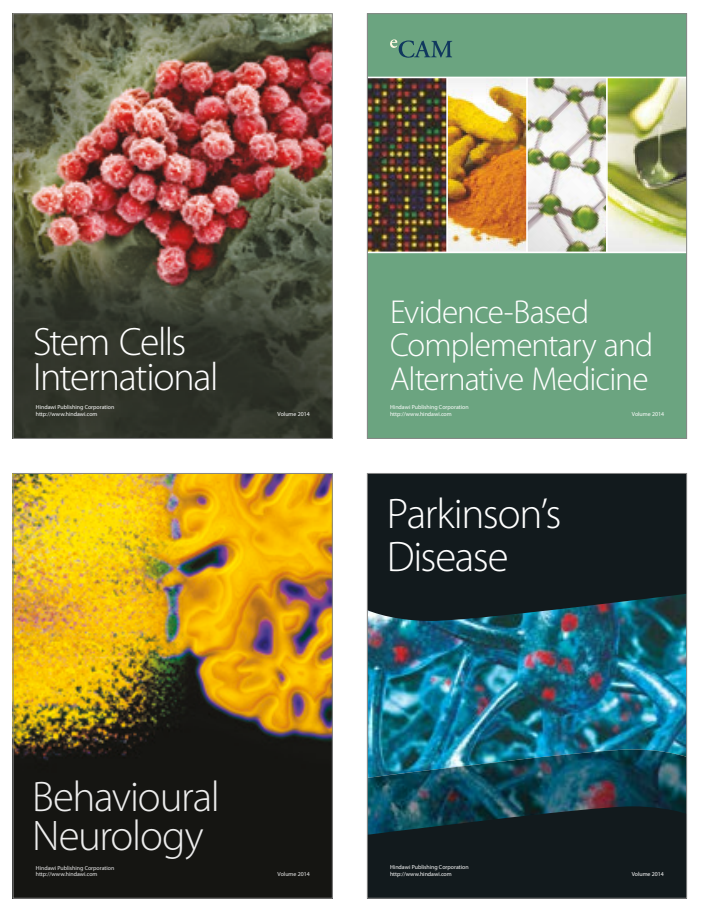
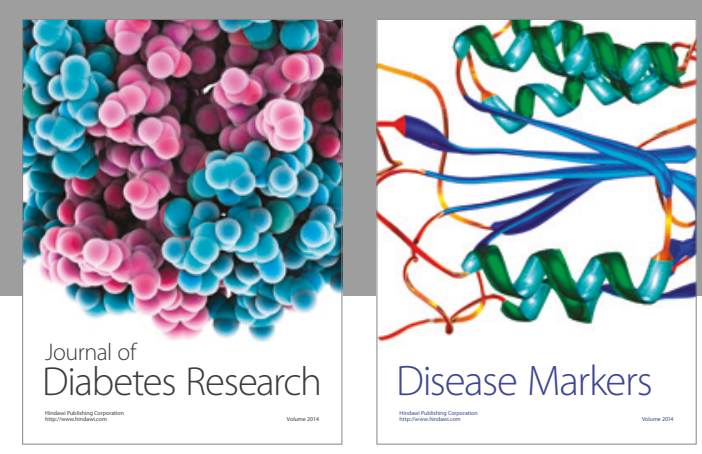

Disease Markers
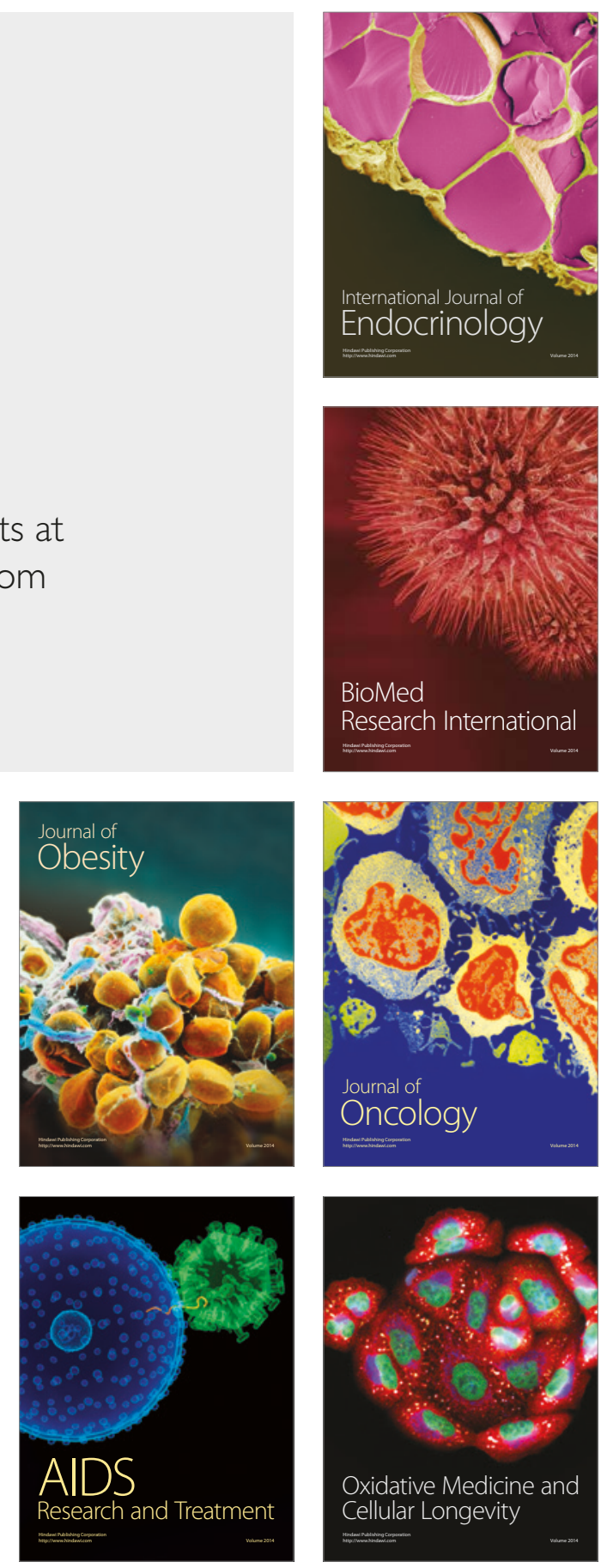